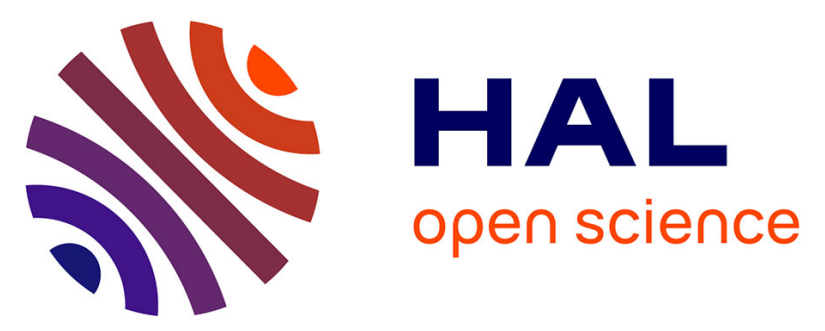

\title{
Modification in light absorption cross section of laboratory-generated black carbon-brown carbon particles upon surface reaction and hydration
}

\author{
Hui Chen, Dawei Hu, Lin Wang, Abdelwahid Mellouki, Jianmin Chen
}

\section{To cite this version:}

Hui Chen, Dawei Hu, Lin Wang, Abdelwahid Mellouki, Jianmin Chen. Modification in light absorption cross section of laboratory-generated black carbon-brown carbon particles upon surface reaction and hydration. Atmospheric environment, 2015, 116, pp.253-261. 10.1016/j.atmosenv.2015.06.052 . insu01174615

HAL Id: insu-01174615

https://hal-insu.archives-ouvertes.fr/insu-01174615

Submitted on 2 Sep 2015

HAL is a multi-disciplinary open access archive for the deposit and dissemination of scientific research documents, whether they are published or not. The documents may come from teaching and research institutions in France or abroad, or from public or private research centers.
L'archive ouverte pluridisciplinaire HAL, est destinée au dépôt et à la diffusion de documents scientifiques de niveau recherche, publiés ou non, émanant des établissements d'enseignement et de recherche français ou étrangers, des laboratoires publics ou privés. 


\section{Modification in light absorption cross section of}

2 laboratory-generated Black Carbon-Brown Carbon

3 particles upon surface reaction and hydration

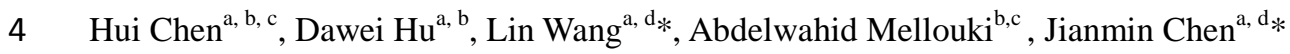

$5{ }^{a}$ Shanghai Key Laboratory of Atmospheric Particle Pollution and Prevention, Department of

6 Environmental Science \& Engineering, Fudan University, 220 Handan Road, Shanghai 200433, China

$7{ }^{b}$ Institut de Combustion, Aérothermique, Réactivité et Environnement, Centre Nationaldela Recherche

8 Scientifique(ICARE-CNRS), 1C, Avenue de la Recherche Scientifique,45071 Orléans cedex 02, France

9 'Observatoire des Sciences de l'Univers en Région Centre(OSUC)-Université d'Orléans, 1 A rue de la

10 Férollerie 45071 Orléans cedex 02, France

$11{ }^{d}$ Fudan Tyndall Centre, Fudan University, 220 Handan Road, Shanghai 200433, China

12 *Corresponding authors: Lin Wang, lin_wang@fudan.edu.cn +86 21 65643568; Jianmin Chen, 13 jmchen@fudan.edu.cn, +862165642298

14

15 Key words: black carbon, brown carbon, light absorption, mixing state, surface 16 reaction 


\section{Abstract}

Recent reports indicate that the absorption enhancement of black carbon (BC) and brown carbon $(\mathrm{BrC})$ particles is determined by the evolution of morphology and mixing state during the atmospheric processing. In this study, laboratory-generated $\mathrm{BC}-\mathrm{BrC}$ mixture particles (BC-BrC) were exposed to sulfuric acid, ammonia/triethylamine, and water vapor sequentially to investigate the alteration in light absorption, morphology and mixing state during simulated atmospheric processing. Condensation of sulfuric acid and exposure to ammonia or triethylamine at $5 \%$ relative humidity decreased light absorption cross section of $\mathrm{BC}-\mathrm{BrC}$ by $13 \%-26 \%$, but subsequent hydration at $85 \%$ relative humidity led to an increase by 5\%-20\%. Our results show that surface reactions and hydration can significantly alter the light absorption cross section of $\mathrm{BC}-\mathrm{BrC}$. Our observation suggests that the restructuring of $\mathrm{BC}-\mathrm{BrC}$ induced by neutralization reactions on the $\mathrm{BC}-\mathrm{BrC}$ surface was responsible for the reduction in light absorption cross section at low relative humidity. On the other hand, the formation of an aqueous coating through water uptake by the hydrophilic inorganic coating at high relative humidity caused an absorption enhancement. 


\section{Introduction}

Black carbon (BC) has now been accepted as a strong absorber of visible solar radiation, leading to a positive (warming) radiative forcing that is estimated to be about one quarter to one half of the magnitude of atmospheric $\mathrm{CO}_{2}$ (Bond et al., 2013; IPCC, 2007; Ramanathan and Carmichael, 2008). Recently, another class of light-absorbing carbon-containing substances (organic carbon, OC) in atmospheric aerosols, namely brown carbon $(\mathrm{BrC})$, arises much scientific interests because its intense absorption at the shorter visible and UV wavelength may lead to underestimation of absorption of solar radiation in the troposphere (Andreae and Gelencsér, 2006).

Annually, 8.0 Tg BC and 33.9 Tg OC are estimated to be emitted at a global scale, and the contributions of biomass/biofuel burning to $\mathrm{BC}$ and $\mathrm{OC}$ are estimated to be $62 \%$ and 93\%, respectively (Bond et al., 2004). Condensable organic species produced from either biomass burning (Lewis et al., 2008) or diffusion flames (Schnaiter et al., 2006), characterized by absorption in the visible light range with an absorption Ångström exponent (AAE) greater than unity, has been linked to the source of $\mathrm{BrC}$. The presence of both $\mathrm{BC}$ and $\mathrm{BrC}$ in particulate matters formed from biomass/biofuel burning at flaming and smoldering conditions complicates the estimation of their climate impacts (Chakrabarty et al., 2010; Kirchstetter et al., 2004; Lack et al., 2012).

Atmospheric processing poses additional uncertainties in estimating the radiative forcing of $\mathrm{BC}$ particles. Once emitted into the atmosphere, BC particles undergo aging processes including condensation of low volatility species, coagulation with pre-existing particles, and potentially, cloud processing. Over a timescale of a few hours to a few days, the aging processes lead to an internal aerosol mixture. Nonrefractory coating in the internally mixed BC particle is believed to act like a lens 
that enhances the light absorption by directing more light towards to the $\mathrm{BC}$ core ("lensing effect"), when compared with an equivalent external mixture (Jacobson, 2001). Theoretically, the extent to which absorption of BC can be enhanced depends critically on the ratio of the mass of nonrefractory particulate matter ([NR-PM]) to that of $\mathrm{BC}([\mathrm{BC}])$ in the internally mixed particle $\left(R_{B C}=[N R-P M] /[B C]\right)($ Bond et al., 2006). A number of ambient studies on optical properties of aged BC (which usually contained amounts of $\mathrm{BrC}$ ) measured absorption enhancement ( $\left.\mathrm{E}_{\mathrm{abs}}\right)$ that differed in a large range from 1.06 to 1.7 with a large scale of $\mathrm{R}_{\mathrm{BC}}$ (Cappa et al., 2012; Knox et al., 2009; Lack et al., 2012). The discrepancy can be partly explained by the different particle configuration caused by various atmospheric aging processes (Adachi and Buseck, 2013; Schnaiter et al., 2003; Schnaiter et al., 2005).

Previous laboratory studies focused on absorption amplification of BC upon condensation of sulfuric acid and organic materials on BC surface (Cross et al., 2010; Schnaiter et al., 2005; Shiraiwa et al., 2010; Zhang et al., 2008). However, the condensed materials are subject to further atmospheric processing, such as surface reactions with gaseous species (Biskos et al., 2009; Wang et al., 2010) and hydration and dehydration cycles (Khalizov et al., 2009; Zhang et al., 2008). Water soluble coating (such as sulfuric acid and glutaric acid) leads to hydration and morphology modification of BC, both of which further amplify their absorption abilities (Khalizov et al., 2009; Mikhailov et al., 2006).

As one of the most abundant secondary chemical components of atmospheric aerosols, sulfate is usually found to be internally mixed with BC. They are believed to alter the morphology, hygroscopicity, and optical properties of BC particles based on the field observation (Fu et al., 2012; Li et al., 2013). However, there were only a few studies on BC internally mixed with ammonium sulfate/bisulfate generated either by 
coagulation (Schnaiter et al., 2003) or by an "evaporation-condensation" procedure (Stratmann et al., 2010). In the real atmosphere, sulfuric acid efficiently sinks on the BC surface (Riemer et al., 2004; Zhang et al., 2008) and subsequently ammonia/amine is transferred to the particulate phase in an effort to neutralize the acidic components forming ammonium/aminium sulfate (Seinfeld and Pandis, 2006). Neutralization of the acidic coating by base gaseous species bring additional mass into the nonrefractory coating (i.e. increase in $\mathrm{R}_{\mathrm{BC}}$ ), which can lead to absorption amplification of BC. On the other hand, neutralization, i.e. transformation of sulfuric acid to ammonium/aminium sulfate/bisulfate could modify the hygroscopicity, density and phase of the overall coating (Chan and Chan, 2012; Qiu and Zhang, 2012; Tang and Munkelwitz, 1994). The influence of neutralization following the condensation of sulfuric acid on BC surface at different relative humidity $(\mathrm{RH})$ is still unclear.

In this study, $\mathrm{BC}$ and $\mathrm{BrC}$ mixture particles $(\mathrm{BC}-\mathrm{BrC})$ were artificially produced from fuel-rich flames. Polycyclic aromatic hydrocarbons (PAHs), as the main OC components of our $\mathrm{BC}-\mathrm{BrC}$, were assigned to $\mathrm{BrC}$ because of their light absorption nature in line with previous investigations on particles from both fuel-rich flames (Apicella et al., 2004; Schnaiter et al., 2006) and wood combustion (Chen and Bond, 2010). We exposed our BC-BrC particles to sulfuric acid $\left(\mathrm{H}_{2} \mathrm{SO}_{4}, \mathrm{SA}\right)$, ammonia $\left(\mathrm{NH}_{3}, \mathrm{AM}\right)$ or triethylamine $\left(\left(\mathrm{CH}_{3} \mathrm{CH}_{2}\right)_{3} \mathrm{~N}, \mathrm{TEA}\right)$, and water vapor sequentially to investigate the absorption and morphology alteration. The procedure simulated transfer of ammonia/amine to the particulate phase by neutralization with condensed sulfuric acid on the $\mathrm{BC}-\mathrm{BrC}$ surface and potential hygroscopic growth of internally mixied $\mathrm{BC}-\mathrm{BrC}$ due to hydrophilic inorganic coating in the atmosphere. Transmission electron microscope (TEM), energy dispersive X-ray spectroscopy (EDX), thermal-evaporation, and Mie calculation using a "core-shell" configuration were 
employed to investigate mechanisms for observed property variation. In addition, potential bias on absorption enhancement owing to the instrumental uncertainties was discussed.

\section{Experimental Methods}

\subsection{Particle generation and characterization}

$\mathrm{BC}-\mathrm{BrC}$ particles were generated in a laminar diffusion burner by combustion of methane $(99.999 \%)$ at a flow rate of $0.2 \mathrm{~L} \mathrm{~min}^{-1}$ and air $(99.999 \%)$ of $0.5 \mathrm{~L} \mathrm{~min}^{-1}$. A flow of $0.05 \mathrm{~L} \mathrm{~min}^{-1}$ was sampled from the chimney and immediately diluted by 20-fold with nitrogen (99.999\%), dried to $<0.5 \% \mathrm{RH}$ by a silica gel diffusion drier and a Nafion tube (Perma pure), and then directed to further experimental usage. Authentic polystyrene latex spheres (PSL, Thermo Scientific) particles were generated using an atomizer (TSI 3670).

The extinction spectra and the chemical composition of $\mathrm{BC}-\mathrm{BrC}$ were measured using an UV-Vis spectrophotometer and a gas chromatography-mass spectrometry (GC-MS), respectively (more details were described in the supplementary information, SI).

Fresh and processed particles were deposited onto a copper grid coated with a carbon film using a single-stage cascade impactor with a 0.5 -mm diameter jet nozzle (Li and Shao, 2010), and analyzed by a transmission electron microscope (Jeol JEM-2100F) at an accelerating voltage of $200 \mathrm{KV}$ and by an energy-dispersive X-ray spectrometer (EDX). A collection time of $30 \mathrm{~s}$ for each EDX spectrum was employed.

\subsection{Processing of $\mathrm{BC}-\mathrm{BrC}$ particles}

Size distributions, mass, and hygroscopicity of particles were measured using a 
system comprising two differential mobility analyzers (DMA, TSI 3081), an aerosol particle mass analyzer (APM, Kanomax 3601), and a condensation particle counter (CPC, TSI 3771), as shown in the supplementary scheme. Briefly, polydisperse particles were brought to charge equilibrium by a Kr-85 neutralizer (TSI 3077), and then size-selected $\left(D_{0}\right)$ by applying a fixed voltage to DMA1 (TSI, 3081). The obtained monodisperse particles (with a geometric standard deviation of 1.07) were exposed to sulfuric acid vapor in a $100 \mathrm{ml}$ reservoir containing $20 \mathrm{ml} 86 \mathrm{wt} \% \mathrm{H}_{2} \mathrm{SO}_{4}$ solution $\left(25 \pm 0.1{ }^{\circ} \mathrm{C}\right)$, directed to a $50 \mathrm{~cm}$ long 10 -cm-i.d. residence chamber (growth reactor), and then through a potassium hydroxide $(\mathrm{KOH})$ scrubber, in which excess $\mathrm{H}_{2} \mathrm{SO}_{4}$ vapor was removed to terminate its condensation. The sulfuric acid-coated particles were exposed to $1 \mathrm{ppm} \mathrm{NH}_{3}$ or $\left(\mathrm{C}_{2} \mathrm{H}_{5}\right)_{3} \mathrm{~N}$ in another $100 \mathrm{ml}$ residence chamber and then to an elevated-RH environment $(5 \%-85 \% \mathrm{RH})$ in a multitube Nafion humidifier (Perma Pure), in which the RH was regulated between 5\% and $85 \%$. In the tandem DMA mode (TDMA), the hygroscopic growth factor $\left(\mathrm{G}_{\mathrm{f}, \mathrm{RH}}\right)$, defined as the ratio of the processed particle diameter $\left(D_{p}\right)$ to the initial one $\left(D_{0}\right)$, was obtained through the inversion of scanning DMA2 data by the TDMA fit program:

$$
G_{f, R H}=\frac{D_{p}}{D_{0}}
$$

The sheath flow in both DMAs was maintained at $6.5 \mathrm{~L} \mathrm{~min}^{-1}$. The aerosol sample flow through DMAs was kept at $1.0 \mathrm{~L} \mathrm{~min}^{-1}$. The $\mathrm{RH}$ was monitored both on the inlet and outlet of DMA2 by two probes (Vaisala HMM22D). The sheath gas in DMA2 was always humidified to an identical $\mathrm{RH}$ to the sample stream to prevent a $\mathrm{RH}$ gradient.

With the presence of a $250{ }^{\circ} \mathrm{C}$ thermal-denuder (TD) placed before DMA2, the shrink in particle size was quantified as $D_{p, 250^{\circ} \mathrm{C}} / D_{0}$ (referred as "heating 
experiment" in the following text). Thermally evaporated organic and inorganic species might re-condense on the particle surface. In our case, re-condensation was expected to be negligible because of the dilution of the sample flow by DMA2 sheath flow and the relatively larger surface areas of the tubing. Additionally, charring of OC was expected insignificant at this temperature (see details in SI).

An APM interfaced with DMA and CPC was used to measure the monodisperse particle mass $\left(m_{p}\right)$ that can be derived from the Gauss fit on the mass distribution recorded in APM-CPC. The mass-mobility scaling exponent $\left(D_{m}\right)$ was derived from the mass mobility relationship $m_{p} \propto d_{m}^{D_{m}}$, where $d_{m}$ was the mobility diameter determined by DMA1. The effective density was derived from the equation $\rho_{\text {eff }}=6 m_{p} / \pi d_{m}^{3}$

Care was taken to minimize adventitious $\mathrm{NH}_{3}$ in the system in order to prevent uncontrolled formation of ammonium sulfate. Ultrahigh pure $\mathrm{N}_{2}(99.999 \%)$ was employed for the flow system. The carrier flow of polydisperse aerosol, the sheath flow in DMAs, and the purge flow in Nafion tubes all passed through $\mathrm{NH}_{3}$-scrubbers, which consisted of a 5 liter-cylindrical reactor filled with granular citric acid. To avoid temperature fluctuation, the entire setup was placed in a temperature controlled box $\left(25 \pm 0.1{ }^{\circ} \mathrm{C}\right)$, and all the connecting tubing was wrapped by thermal-insulated materials.

\subsection{Optical properties measurement}

Optical properties of fresh and processed monodisperse particles with an initial diameter of $150 \mathrm{~nm}$ were measured using a combination of a self-made cavity ring-down spectroscopy (CRDS) and a nephelometer (TSI 3563) interfaced to a CPC (TSI 3776) (Li et al., 2011; Li et al., 2013). Total extinction coefficient $\left(\sigma_{\text {ext }}\right)$ was 
determined at $532 \mathrm{~nm}$ by the CRDS, and total scattering coefficient was measured at 450,550 , and $700 \mathrm{~nm}$ by the nephelometer. The scattering coefficient was corrected for angular nonidealities using the scheme reported in Anderson and Ogren (1998) and converted to $532 \mathrm{~nm}\left(\sigma_{\text {scat }}\right)$ using the Ångström exponent equation:

$$
\stackrel{\operatorname{a}}{a}=-\frac{\log \left(\sigma_{\text {scat }, 532} / \sigma_{\text {scat }, 550}\right)}{\log (532 / 550)} .
$$

In the present study, the method yielded a correction factor of $1.00 \pm 0.01$. The scattering Ångström coefficients ranged from 3.43 to 3.56 for fresh and processed $\mathrm{BC}-\mathrm{BrC}$ (details in SI).

Particle number concentration measured by CPC was used together with extinction and scattering coefficient to calculate the corresponding cross section: $C_{\text {ext } / s c a t}=\frac{\sigma_{\text {ext } / \text { scat }}}{N}$, where $C$ was the cross section and $N$ was the particle number concentration corrected with the diffusion loss in either CRDS or nephelometer.

The absorption coefficient $\left(\sigma_{a b s}\right)$ at $532 \mathrm{~nm}$ was then calculated from the difference between the extinction and scattering coefficient. By using this "extinction-minus-scattering" method, the absorption coefficient could be overestimated at high relative humidity. With up to $2{ }^{\circ} \mathrm{C}$ difference between the inlet and the body of nephelometer, the humidity in the body was estimated to be $78 \%$ when the inlet gave a $\mathrm{RH}$ of $85 \%$. Since alteration in complex refractive indices was expected to be low over this $\mathrm{RH}$ range $(78 \%-85 \%)$, the scattering coefficient solely scaled according to the $4^{\text {th }}$ or $5^{\text {th }}$ power with the particle diameter in this size range. The sulfate coatings were expected to be aqueous in $78 \%-85 \% \mathrm{RH}$ range since the highest efflorescence $\mathrm{RH}$ among the three forms of coating was reported $\sim 35 \%$ for ammonium sulfate (Tang and Munkelwitz, 1994). By estimating the particle size decrease from the interpolated hygroscopic growth curve measured by TDMA (see 
section 3.4), measured scattering (78\% RH in the body) was corrected by a factor of

207 1.07-1.09 according to $\left(\frac{D_{p, 85 \%}}{D_{p, 78 \%}}\right)^{5}$ to derive that at $85 \% \mathrm{RH}$. On the other hand, such

212 during the aging was obtained according to $E_{a b s}=\frac{C_{a b s, \text { processed BC-BrC }}}{C_{a b s, \text { fresh BC-BrC }}}$. temperature difference-induced correction is unnecessary for CRDS measurements. Hence, absorption cross section and single scattering albedo (SSA) are values at $85 \%$ RH.

SSA was calculated according to $S S A=C_{\text {scat }} / C_{e x t}$. Enhancement of absorption Overestimation of singly charged particles of $150 \mathrm{~nm}$ from DMA1 due to doubly charged particles was $\sim 1 \%$ as calculated from the particle size distribution (Figure S1) and the charging efficiency. Bias from doubly charged large particles was $<7 \%$ and $<3 \%$ in scattering and absorption measurement, respectively. No correction due to multiply charged particles was applied.

\section{Results and Discussions}

\subsection{Basics of BC-BrC particles}

$\mathrm{BC}-\mathrm{BrC}$ particles in the size range of 30-250 $\mathrm{nm}$ (a count median diameter at 69 $\mathrm{nm}$ and a geometric standard deviation $\sigma_{g}$ of 1.24) were generated from a fuel-rich flame $\left(\mathrm{V}_{\text {methane }} / \mathrm{V}_{\text {air }}=0.4\right)$ in a laminar diffusion burner. An extinction Ångström coefficient of 2.9 was determined for the emulsion of $\mathrm{BC}-\mathrm{BrC}$ in dichloromethane in the wavelength range of $250-800 \mathrm{~nm}$. This significant spectral dependence was mainly attributable to the absorption by the dissolved $\mathrm{OC}$ fraction assigned to $\mathrm{BrC}$ in accordance to a series of PAHs detected by GC-MS. Similar spectral dependence due 
to $\mathrm{BrC}$ fraction with similar chemical composition has been also observed for wood combustion aerosol (Chen and Bond, 2010).

Mass of monodisperse BC-BrC particles (40, 100 and $150 \mathrm{~nm}$ ) was measured by the DMA-APM system. The obtained mass-mobility scaling exponent of 2.9 suggested near-spherical (3.0 for a sphere) rather than fractal-like shape (Slowik et al., 2004). The effective density was determined to be $1.10-1.27 \mathrm{~g} / \mathrm{cm}^{3}$, with smaller values for larger particles. The values are smaller than the recommended $\mathrm{BC}$ material density of $1.8 \mathrm{~g} / \mathrm{cm}^{3}$ (Bond and Bergstrom, 2006) and typical PAHs density of 1.3 $\mathrm{g} / \mathrm{cm}^{3}$, but larger than $0.8 \mathrm{~g} / \mathrm{cm}^{3}$ for compact soot aggregates obtained through condensation of sulfuric acid and subsequent heating (Khalizov et al., 2009), indicating either that internal voids existed or that the particles comprised a great amount of aliphatics (typical density of $0.8 \mathrm{~g} / \mathrm{cm}^{3}$ ). Since combustion particles produced under similar conditions contains minor amounts $(\sim 5 \%)$ of aliphatics (Slowik et al., 2004), which was also evidenced from our GC-MS analysis, we speculate that internal voids were present in our $\mathrm{BC}-\mathrm{BrC}$ particles in spite of their near-spherical shape. By applying and not applying a thermal denuder in front of APM, organic species in $\mathrm{BC}-\mathrm{BrC}$ volatilized at $250{ }^{\circ} \mathrm{C}$ in a $\mathrm{N}_{2}$ atmosphere was determined to be $34 \%-54 \%$, with smaller values for larger particles.

\subsection{Alteration in optical properties}

We exposed monodisperse $\mathrm{BC}-\mathrm{BrC}$ particles $(150 \mathrm{~nm})$ to $\mathrm{H}_{2} \mathrm{SO}_{4}$ vapor, eliminated excess $\mathrm{H}_{2} \mathrm{SO}_{4}$ vapor using a $\mathrm{KOH}$ trap, exposed the $\mathrm{H}_{2} \mathrm{SO}_{4}$-coated particles (BC-BrC-SA) to $\mathrm{NH}_{3}$ or $\left(\mathrm{CH}_{3} \mathrm{CH}_{2}\right)_{3} \mathrm{~N}$ gas, and modulated the concentration of water vapor to allow any potential hygroscopic growth. Excess base gases were retained in the system to ensure base gases were always available for neutralization during the entire morphology transformation process of BC-BrC-SA. Optical properties of fresh 
and processed particles were then measured using a combination of nephelometer and CRDS at dry (5\% RH) and wet (85\% RH) conditions, respectively (Fig. 1a). Fresh BC-BrC showed a mass absorption efficiency (the ratio of absorption cross section to the mass of $\mathrm{BC}-\mathrm{BrC}$ particle) of $3.2 \pm 0.5 \mathrm{~m}^{2} \mathrm{~g}^{-1}$ at $532 \mathrm{~nm}$, and a mass scattering efficiency of $2.7 \pm 0.3 \mathrm{~m}^{2} \mathrm{~g}^{-1}$. The mass absorption efficiency of BC-BrC is much lower than that of typical fresh soot because of the presence of organic materials (Schnaiter et al., 2006), resulting in a single scattering albedo of $0.46 \pm 0.04$ that is significantly larger than fresh soot (0.2-0.3) (Bond and Bergstrom, 2006).

When $\mathrm{BC}-\mathrm{BrC}$ were coated with $\mathrm{H}_{2} \mathrm{SO}_{4}$, and subsequently completely or partially neutralized with $\mathrm{NH}_{3}$ or $\left(\mathrm{C}_{2} \mathrm{H}_{5}\right)_{3} \mathrm{~N}$, the fraction of nonrefractory coating led to the variation in light absorption, which depended on the coating components and the relative humidity (Fig. 1b, and Table $\mathrm{S} 2$ ). At $5 \% \mathrm{RH}, \mathrm{E}_{\mathrm{abs}}$ showed values of $0.87,0.85$, and 0.74 for three coatings, respectively, suggesting that condensation of inorganic acid and subsequent surface neutralization reactions were able to decrease the light absorption cross section of $\mathrm{BC}-\mathrm{BrC}$ at dry conditions. The observation was contrary to the theoretical prediction that addition of nonrefractory coating would lead to increase in light absorption. The reduction in light absorption was plausibly attributable to restructuring of $\mathrm{BC}-\mathrm{BrC}$ caused by the processing. Restructuring of fractal-like $\mathrm{BC}$ act either to amplify light absorption owing to enhanced interaction between neighboring spherules, or to reduce absorption due to inner spherules shielded by the outer ones (Liu et al., 2008). The shielding effect appears to be significant for particles with volume equivalent diameter $>180 \mathrm{~nm}$ or $>80 \mathrm{~nm}$ suggested by theoretical prediction (Liu et al., 2008) or experimental investigation (Khalizov et al., 2009), respectively. In the present study, condensed OC components might deprive the fractal-like shape but not necessarily compressed the BC inclusion into spheres in 
fresh BC-BrC particles, which accorded with from Slowik et al. (2007) that

anthracene didn't cause measurable restructuring of fractal like soot aggregates. Restructuring of $\mathrm{BC}-\mathrm{BrC}$ and $\mathrm{BC}$ inclusion was evidenced by heating experiment (section 3.5) in spite of their near-spherical shape.

An elevation in relative humidity to $85 \%$, however, led to $\mathrm{E}_{\mathrm{abs}}$ of $1.05,1.20$ and 1.18, respectively, in accordance with previous studies that hydration(Schwarz et al., 2008) can enhance light absorption of internally-mixed hydrophilic soot (Khalizov et al., 2009; Mikhailov et al., 2006). Condensed sulfuric acid or its reaction products with base gases can uptake amounts of water at $85 \% \mathrm{RH}$ and form transparent shell over $\mathrm{BC}-\mathrm{BrC}$ particles, which is expected to enhance the lensing effect that surpassed the shielding effect of $\mathrm{BC}-\mathrm{BrC}$ restructuring, resulting in a net absorption increase. On the other hand, Lewis et al. (2009) reported a reduction in light absorption of biomass burning aerosol upon humidification, which was hypothesized to arise either from the shielding effect due to particle collapse induced from water uptake by intrinsic inorganic components, or from the instrumental artifact due to photoacoustic heat and mass transfer.

The scattering of $\mathrm{BC}-\mathrm{BrC}$ particles did not change at $5 \% \mathrm{RH}$ but increased by 1.1-fold at $85 \%$ RH (Fig. 1a), which was much weaker compared with previous studies on glutaric acid- or $\mathrm{H}_{2} \mathrm{SO}_{4}$-coated chain $\mathrm{BC}$ agglomerates (Khalizov et al., 2009; Mikhailov et al., 2006). Fresh BC agglomerates consisted of small primary spherules $(15-25 \mathrm{~nm})$ that weakly scattered light, and the restructuring and volume growth due to condensation and hydration led to a more compact shape with much stronger scattering (Khalizov et al., 2009), which did not occur for processed BC-BrC particles in this study. 


\subsection{TEM and EDX analysis}

TEM and EDX were used to study the morphology of BC-BrC. The majority of fresh $\mathrm{BC}-\mathrm{BrC}$ indicated a configuration similar to embedded soot that is heavily coated by condensed organic materials emitted from wildfire (China et al., 2013), while a small fraction showed partially coated chain agglomerates (Fig. 2b) as aggregates of primary particles (China et al., 2013). Due to the deformation of particles during the collection and under TEM vacuum, the internal voids of fresh $\mathrm{BC}-\mathrm{BrC}$ cannot be visualized under TEM. The $\mathrm{H}_{2} \mathrm{SO}_{4}$ coating did not alter particle morphology significantly, and the $\mathrm{H}_{2} \mathrm{SO}_{4}$ coating itself was not quite visualized in TEM images because of the evaporation of $\mathrm{H}_{2} \mathrm{SO}_{4}$ under vacuum (Fig. 2c). Neutralization by $\mathrm{NH}_{3}$ or $\left(\mathrm{C}_{2} \mathrm{H}_{5}\right)_{3} \mathrm{~N}$, however, brought on identifiable coating on $\mathrm{BC}-\mathrm{BrC}$ particle surface (Figs. 2d and 2e), which was likely at least partially responsible for the modified optical properties of particles. Note that the BC-BrC-SA-AM particle in Fig. 2d was exposed to $85 \% \mathrm{RH}$ before collection, and hence the circular spot around the particle was attributable to a residue of ammonium sulfate after the evaporation of most of the ammonium sulfate solution. The image might reflect an ideal "core-shell" configuration with $\mathrm{BC}-\mathrm{BrC}$ located at the center and inorganic coating in the surrounding. EDX spectra revealed the presence of various elements (Figs. $2 \mathrm{f}$ and $2 \mathrm{~g}$ ).

Carbon elements mainly came from $\mathrm{BC}-\mathrm{BrC}$, while oxygen, silicon, and copper were from the Si-O substrate and the impactor grid ( $\mathrm{Li}$ and Shao, 2010). In contrast to TEM tests, minor sulfur element was evidenced in EDX spectra for $\mathrm{BC}-\mathrm{BrC}-\mathrm{SA}$, suggesting the presence of $\mathrm{H}_{2} \mathrm{SO}_{4}$ residue after evaporation of most condensed $\mathrm{H}_{2} \mathrm{SO}_{4}$ under vacuum, or the presence of other sulfur-containing species. Sulfur element was more abundant in EDX spectra for $\mathrm{BC}-\mathrm{BrC}-\mathrm{SA}-\mathrm{AM}$, since $\mathrm{H}_{2} \mathrm{SO}_{4}$ was neutralized to less-volatile $\left(\mathrm{NH}_{4}\right)_{2} \mathrm{SO}_{4}$. Restricted by detection limit and resolution, $\mathrm{N}$ elements from 
ammonium ions were undetectable by EDX (Li and Shao, 2010).

\subsection{Physicochemical properties of hydrophilic inorganic coating}

In Figure 3, the size variation of $150 \mathrm{~nm} \mathrm{BC-BrC}$ was plotted, as well as that of authentic PSL particles as a reference, when processed with $\mathrm{H}_{2} \mathrm{SO}_{4}, \mathrm{NH}_{3}$ or $\left(\mathrm{CH}_{3} \mathrm{CH}_{2}\right)_{3} \mathrm{~N}$, and water vapor. Similar figures for 40 and $100 \mathrm{~nm}$ particles are presented in Fig. S4. Except for two cases of $40 \mathrm{~nm}$ particles at the highest RH (Fig. 3 and Fig. S4), the mobility diameters of processed $\mathrm{BC}-\mathrm{BrC}$ were always smaller than those of PSL, indicating morphology alteration during the processing including condensation, surface reaction, and hydration. Morphology alteration can be caused by combined effects of particle restructuring and a decrease in the dynamic shape factor. The latter was explained by the padding of small cavities by inorganic coating on the irregular particle surface. However, the actual cause for the decrease in mobility size of BC-BrC-SA, -SA-AM, and -SA-TEA was concealed because the alteration in effective density of $\mathrm{BC}-\mathrm{BrC}$ due to different processing was unavailable.

As shown in Fig. 3 and in Fig. S4, BC-BrC-SA, -SA-AM and-SA-TEA have shown distinctive, i.e., either continuous or deliquescent, hygroscopic growth curves, which was largely determined by the nature of inorganic coatings. As reported by Stratmann et al. (2010), evaporation-condensation procedure generates ammonium bisulfate coating rather than ammonium sulfate. Without a direct measurement, the chemical composition in the coating was then evaluated by combining the hygroscopic growth factors of processed PSL and physicochemical properties of ammonium/aminium sulfates/bisulfates derived from E-AIM model (see details in SI).

The amounts of sulfate ions in the coating of processed PSL were identical for PSL-SA at the RH range of $30 \%-85 \%$ and PSL-SA-AM/TEA at $85 \% \mathrm{RH}$, i.e., the occurrence of deliquescence and the formation of an ammonium or triethylaminium 
sulfate (AS or TEAS) solution (Table S3a). The seeming larger number of sulfate ions for $\mathrm{NH}_{3}$ exposure at $5 \%, 30 \%$, and $70 \% \mathrm{RH}$ was rationalized by the AS coating being in fact crystalline and nonuniform under dry condition. In this case, the diameter sized by DMA was larger than that of a sphere equivalent in volume (Gibson et al., 2007), which resulted in an effective density of AS coating less than that of authentic standards (Table S3a). Hence, within experimental uncertainty, $\mathrm{NH}_{3}$ gas was able to completely neutralize coated $\mathrm{H}_{2} \mathrm{SO}_{4}$ at all relative humidity used.

In contrast, the calculated number of sulfate ions for $\left(\mathrm{CH}_{3} \mathrm{CH}_{2}\right)_{3} \mathrm{~N}$ exposure at $5 \%$, $30 \%$ and $70 \% \mathrm{RH}$ was smaller than those in the $\mathrm{H}_{2} \mathrm{SO}_{4}$ coating if complete neutralization was assumed (Table S3b and Fig. S5). This discrepancy suggested that $\mathrm{H}_{2} \mathrm{SO}_{4}$ was only partially neutralized by $\left(\mathrm{CH}_{3} \mathrm{CH}_{2}\right)_{3} \mathrm{~N}$ at low humidity, because the initial reactions between condensed $\mathrm{H}_{2} \mathrm{SO}_{4}$ and gaseous $\left(\mathrm{CH}_{3} \mathrm{CH}_{2}\right)_{3} \mathrm{~N}$ led to formation of triethylaminium bisulfate/sulfate (TEABS/TEAS) on the particle surface and the steric hindrance of ethyl groups in TEABS/TEAS prevented gaseous $\left(\mathrm{CH}_{3} \mathrm{CH}_{2}\right)_{3} \mathrm{~N}$, although still available, from diffusing deep into $\mathrm{H}_{2} \mathrm{SO}_{4}$ liquid layer to achieve complete neutralization. Further uptake gaseous $\left(\mathrm{CH}_{3} \mathrm{CH}_{2}\right)_{3} \mathrm{~N}$ and complete neutralization did not occur until high relative humidity was reached (Chan and Chan, 2012).

Hence, the formation of AS on PSL surface is responsible for the deliquescent behavior for PSL-SA-AM, whereas the evolving chemical composition and hydrophobic ethyl group terminal explains the non-growth for PSL-SA-TEA until 85\% $\mathrm{RH}$ in contrast to continuous hygroscopic growth of atomized particles (Qiu and Zhang, 2012), or droplets from TEAS or TEABS solutions (Chan and Chan, 2012). Once the relative humidity rose to $85 \%$, a solution layer of AS or TEAS was formed on the $\mathrm{BC}-\mathrm{BrC}$ particle surface and demonstrated mainly its lensing effect. 


\subsection{Thermal removal of volatile compounds}

Fresh and processed $\mathrm{BC}-\mathrm{BrC}$ particles was heated up to $250{ }^{\circ} \mathrm{C}$ in a $\mathrm{N}_{2}$ atmosphere and the variation in particle diameter was measured to further investigate the morphology variation of the refractory core of $\mathrm{BC}-\mathrm{BrC}$ particles during the aging process (Fig. 4). Heating led to removal of semi-volatile and/or low volatility compounds, and the extent of shrinking in size decreased with increasing $\mathrm{D}_{0}$. Coating of $\mathrm{H}_{2} \mathrm{SO}_{4}$ followed by heating, i.e., heating of BC-BrC-SA, however, resulted in larger particles than heated $\mathrm{BC}-\mathrm{BrC}$. Since sulfuric acid is expected to evaporate at $250{ }^{\circ} \mathrm{C}$ (Cross et al., 2010), the relative increase in diameter can be explained by formation of small amounts of refractory sulfur-containing species upon coating of $\mathrm{H}_{2} \mathrm{SO}_{4}$ or during heating, as suggested by our EDX spectra.

In addition, heated BC-BrC-SA were generally larger than heated BC-BrC-SA-AM and BC-BrC-SA-TEA, suggesting BC-BrC collapsed to various extent owing to the neutralization by $\mathrm{NH}_{3}$ and $\left(\mathrm{CH}_{3} \mathrm{CH}_{2}\right)_{3} \mathrm{~N}$. The extent of reduction in light absorption cross section for BC-BrC-SA-AM/-TEA coincided with the extent of shrinking of refractory core, indicating that collapse of refractory core (i.e. BC inclusion) was likely responsible for the reduction in light absorption cross section at $5 \%$ RH. Exposure of fresh and coated particles to $85 \%$ relative humidity before heating led to further shrinking of particles, however, the extent is rather small comparing to that due to coating. Hence, compacting of $\mathrm{BC}-\mathrm{BrC}$ exerted a more profound role at the initial stage of our simulated aging, i.e., condensation and surface reactions.

\subsection{Mie theory calculation with a core-shell configuration}

Mie theory with a core-shell configuration has been widely applied to evaluate the absorption alteration of internally mixed BC (Bohren and Huffman, 2007; Bond et 
al., 2006; Schnaiter et al., 2005). In our study, the effect of different sulfate coatings on absorption enhancement was investigated using this method. Briefly, the model utilized a volume equivalent diameter of $132.7 \mathrm{~nm}$ estimated from the effective density and $\mathrm{OC}$ fraction, a complex refractive index of $2.0+0.2 \mathrm{i}$ for the $\mathrm{BC}-\mathrm{BrC}$ core retrieved from Mie "closure" calculations using measured absorption and scattering coefficients (Chakrabarty et al., 2010), and the complex refractive indices of sulfates coating according to the volume weighted mixing rule (see more details in SI).

Our calculation results are presented in Fig. 5. Generally, $E_{a b s}$ was always larger than 1 and increased monotonously in the entire range of $\mathrm{R}_{\mathrm{BC}-\mathrm{BrC}}$ in line with Bond et al. (2006). Hydration can significantly enhance light absorption by increasing the coating mass; on the other hand, it can narrow the difference in $\mathrm{E}_{\mathrm{abs}}$ among different forms of sulfates because their water uptake ability was close at high humidity.

Our measured $E_{a b s}$ is presented in Fig. 5 for comparison. The nonrefractory coating mass was derived from that of processed PSL (see section 3.4 and Table S3). The overall uncertainty of $\mathrm{R}_{\mathrm{BC}-\mathrm{BrC}}$ was estimated to be $30 \%$, taking into account the surface nature and morphology. The uncertainty of $\mathrm{E}_{\mathrm{abs}}$ was estimated to be equal to the relative errors of $\sigma_{\mathrm{abs}}$ measurement (see more details in SI). Clearly, the "core-shell" configuration calculation fairly reproduce the $\mathrm{E}_{\mathrm{abs}}$ at $85 \% \mathrm{RH}$ but overestimates $\mathrm{E}_{\mathrm{abs}}$ at $5 \% \mathrm{RH}$, likely because the model didn't involve other key facts including particle shape alteration and interaction between OC and inorganic coatings. Schnaiter et al. (2005) also reported less well reproducibility of Mie theory calculation for SOA-coated BC than for pure SOA, most likely because of the restructuring and the incomplete enclosure of the porous soot aggregates. 


\section{Conclusion}

Our work on the multistep processing of $\mathrm{BC}-\mathrm{BrC}$, which utilized condensation of $\mathrm{H}_{2} \mathrm{SO}_{4}$ and subsequent neutralization and hydration, provides an attempt to mimic the real sequence of atmospheric aging events and to investigate the corresponding alteration in BC-BrC's light absorption, as shown in Fig. 6. Our study suggests that surface reactions can modify the mixing state and morphology of $\mathrm{BC}-\mathrm{BrC}$. The restructuring of $\mathrm{BC}-\mathrm{BrC}$ largely determines the light absorption ability at low humidity even if neutralization of SA-coating by $\mathrm{NH}_{3}$ or $\left(\mathrm{CH}_{3} \mathrm{CH}_{2}\right)_{3} \mathrm{~N}$ causes mass growth of nonrefractory coating. Heating experiments could not verify he restructuring of $\mathrm{BC}-\mathrm{BrC}$ induced by condensation of sulfuric acid because of the formation of refractory sulfur-containing species, while it was evident that neutralization of $\mathrm{NH}_{3}$ or $\left(\mathrm{CH}_{3} \mathrm{CH}_{2}\right)_{3} \mathrm{~N}$ with condensed $\mathrm{H}_{2} \mathrm{SO}_{4}$ act to compact the $\mathrm{BC}$ inclusion. Meanwhile, ammonium sulfate coating originated from reaction between $\mathrm{SA}$ and $\mathrm{NH}_{3}$ on the surface was evidenced to be nonuniform, which was different from the core-shell configuration and correspondingly hindered the lensing effect. In addition, the effect of high relative humidity in the evolution of internally mixed BC and/or $\mathrm{BrC}$ has been investigated in this work. Above the deliquescence relative humidity, hydrophilic sulfate coating will exert primarily lensing effect that enhances absorption although shielding effect is also occurring.

The presence of $\mathrm{OC}$ in $\mathrm{BC}-\mathrm{BrC}$ particles and their interaction with coating materials turned to be a source of the complexities. Henning et al. (2012) recently reported an increase of the hygroscopic growth with increasing OC-content for CAST-soot internally mixed with sulfuric acid, which arose the hypothesis that sulfuric acid reacts with PAHs and form hydrophilic products. The speculated reaction between sulfuric acid and PAHs would modify the light absorption in the UV-Vis 
range for $\mathrm{BC}-\mathrm{BrC}$ particles in addition to their hygroscopicity. In our study, the discrepancy between experimental data and Mie theory calculation with a core-shell model configuration might originate from the interaction between $\mathrm{OC}$ and inorganic coating under different humidity conditions in addition to the $\mathrm{BC}-\mathrm{BrC}$ restructuring.

It is now accepted that $\mathrm{BC}$ and/or $\mathrm{BrC}$, freshly emitted from incomplete combustion processes, will become eventually internally mixed with secondary organic aerosols, sulfates, and nitrates (Moffet and Prather, 2009; Posfai et al., 1999). Our study suggested that various chemical processing largely determined the alteration in mixing state, morphology and light absorption of BC-BrC. Hence, other important surface reaction processes, e.g., the formation of ammonium nitrate following the sulfate coating, should be investigated (Riemer et al., 2004). In addition, the extent of alteration in light absorption cross section for $\mathrm{BC}-\mathrm{BrC}$ should be cautiously extrapolated to their real climate impact because internally mixed $\mathrm{BC} / \mathrm{BrC}$ usually contained more nonrefractory materials, i.e. large $\mathrm{R}_{\mathrm{BC}}$. Clearly, the whole picture of the evolution of $\mathrm{BC} / \mathrm{BrC}$ is yet to be completely understood.

\section{Acknowledgements}

This work was financially supported by National Natural Science Foundation of China (21190053, 21222703), Science \& Technology Commission of Shanghai Municipality (12DJ1400100, 13XD1400700), Strategic Priority Research Program of the Chinese Academy of Sciences (XDB05010200), Ph.D. Programs Foundation of Ministry of Education of China (20110071130003, 20120071110023), FP7 project (AMIS, PIRSES-GA-2011, project $\mathrm{N}^{\circ}$ 295132) and Labex VOLTAIRE (ANR-10-LABEX-100-01). 


\section{References}

Adachi, K., Buseck, P.R., 2013. Changes of ns-soot mixing states and shapes in an urban area during CalNex. J. Geophys. Res. D: Atmos. 118, 3723-3730.

Anderson, T.L., Ogren, J.A., 1998. Determining aerosol radiative properties using the TSI 3563 integrating nephelometer. Aerosol. Sci. Technol. 29, 57-69.

Andreae, M.O., Gelencsér, A., 2006. Black carbon or brown carbon? The nature of light-absorbing carbonaceous aerosols. Atmos. Chem. Phys. 6, 3131-3148.

Apicella, B., Alfe, M., Barbella, R., Tregrossi, A., Ciajolo, A., 2004. Aromatic structures of carbonaceous materials and soot inferred by spectroscopic analysis. Carbon 42, 1583-1589.

Biskos, G., Buseck, P.R., Martin, S.T., 2009. Hygroscopic growth of nucleation-mode acidic sulfate particles. J. Aerosol. Sci. 40, 338-347.

Bohren, C.F., Huffman, D.R., 2007. Absorption and Scattering of Light by Small Particles. Wiley-VCH Verlag GmbH, pp. i-xiv.

Bond, T.C., Bergstrom, R.W., 2006. Light absorption by carbonaceous particles: An investigative review. Aerosol. Sci. Technol. 40, 27-67.

Bond, T.C., Doherty, S.J., Fahey, D.W., Forster, P.M., Berntsen, T., DeAngelo, B.J., Flanner, M.G., Ghan, S., Karcher, B., Koch, D., Kinne, S., Kondo, Y., Quinn, P.K., Sarofim, M.C., Schultz, M.G., Schulz, M., Venkataraman, C., Zhang, H., Zhang, S., Bellouin, N., Guttikunda, S.K., Hopke, P.K., Jacobson, M.Z., Kaiser, J.W., Klimont, Z., Lohmann, U., Schwarz, J.P., Shindell, D., Storelvmo, T., Warren, S.G., Zender, C.S., 2013. Bounding the role of black carbon in the climate system: A scientific assessment. J. Geophys. Res. D: Atmos. 118, 5380-5552.

Bond, T.C., Habib, G., Bergstrom, R.W., 2006. Limitations in the enhancement of visible light absorption due to mixing state. J. Geophys. Res. D: Atmos. 111, D20211.

Bond, T.C., Streets, D.G., Yarber, K.F., Nelson, S.M., Woo, J.-H., Klimont, Z., 2004. A technology-based global inventory of black and organic carbon emissions from combustion. J. Geophys. Res. D: Atmos. 109, D14203.

Cappa, C.D., Onasch, T.B., Massoli, P., Worsnop, D.R., Bates, T.S., Cross, E.S., Davidovits, P., Hakala, J., Hayden, K.L., Jobson, B.T., Kolesar, K.R., Lack, D.A., Lerner, B.M., Li, S.M., Mellon, D., Nuaaman, I., Olfert, J.S., Petaja, T., Quinn, P.K., Song, C., Subramanian, R., Williams, E.J., Zaveri, R.A., 2012. Radiative absorption enhancements due to the mixing state of atmospheric black carbon. Science 337, 1078-1081.

Chakrabarty, R.K., Moosmüller, H., Chen, L.W.A., Lewis, K., Arnott, W.P., Mazzoleni, C., Dubey, M.K., Wold, C.E., Hao, W.M., Kreidenweis, S.M., 2010. Brown carbon in tar balls from smoldering biomass combustion. Atmos. Chem. Phys. 10, 6363-6370.

Chan, L.P., Chan, C.K., 2012. Displacement of ammonium from aerosol particles by uptake of triethylamine. Aerosol. Sci. Technol. 46, 236-247. 
Chen, Y., Bond, T.C., 2010. Light absorption by organic carbon from wood combustion. Atmos. Chem. Phys. 10, 1773-1787.

China, S., Mazzoleni, C., Gorkowski, K., Aiken, A.C., Dubey, M.K., 2013. Morphology and mixing state of individual freshly emitted wildfire carbonaceous particles. Nat. Commun. 4, 2122.

Cross, E.S., Onasch, T.B., Ahern, A., Wrobel, W., Slowik, J.G., Olfert, J., Lack, D.A., Massoli, P., Cappa, C.D., Schwarz, J.P., Spackman, J.R., Fahey, D.W., Sedlacek, A., Trimborn, A., Jayne, J.T., Freedman, A., Williams, L.R., Ng, N.L., Mazzoleni, C., Dubey, M., Brem, B., Kok, G., Subramanian, R., Freitag, S., Clarke, A., Thornhill, D., Marr, L.C., Kolb, C.E., Worsnop, D.R., Davidovits, P., 2010. Soot particle studies-Instrument inter-comparison-Project overview. Aerosol. Sci. Technol. 44, 592-611.

Fu, H., Zhang, M., Li, W., Chen, J., Wang, L., Quan, X., Wang, W., 2012. Morphology, composition and mixing state of individual carbonaceous aerosol in urban Shanghai. Atmos. Chem. Phys. 12, 693-707.

Gibson, E.R., Gierlus, K.M., Hudson, P.K., Grassian, V.H., 2007. Generation of Internally Mixed Insoluble and Soluble Aerosol Particles to Investigate the Impact of Atmospheric Aging and Heterogeneous Processing on the CCN Activity of Mineral Dust Aerosol. Aerosol. Sci. Technol. 41, 914-924.

Henning, S., Ziese, M., Kiselev, A., Saathoff, H., Möhler, O., Mentel, T.F., Buchholz, A., Spindler, C., Michaud, V., Monier, M., Sellegri, K., Stratmann, F., 2012. Hygroscopic growth and droplet activation of soot particles: uncoated, succinic or sulfuric acid coated. Atmos. Chem. Phys. 12, 4525-4537.

IPCC, 2007. Intergovernmental Climate Change Report. Cambridge Univ Press, Cambridge, UK.

Jacobson, M.Z., 2001. Strong radiative heating due to the mixing state of black carbon in atmospheric aerosols. Nature 409, 695-697.

Khalizov, A.F., Xue, H., Wang, L., Zheng, J., Zhang, R., 2009. Enhanced light absorption and scattering by carbon soot aerosol internally mixed with sulfuric acid. J. Phys. Chem. A 113, 1066-1074.

Kirchstetter, T.W., Novakov, T., Hobbs, P.V., 2004. Evidence that the spectral dependence of light absorption by aerosols is affected by organic carbon. J. Geophys. Res. D: Atmos. 109, D21208.

Knox, A., Evans, G.J., Brook, J.R., Yao, X., Jeong, C.H., Godri, K.J., Sabaliauskas, K., Slowik, J.G., 2009. Mass Absorption Cross-Section of Ambient Black Carbon Aerosol in Relation to Chemical Age. Aerosol Sci. Technol. 43, 522-532.

Lack, D.A., Langridge, J.M., Bahreini, R., Cappa, C.D., Middlebrook, A.M., Schwarz, J.P., 2012. Brown carbon and internal mixing in biomass burning particles. Proc. Nat. Acad. Sci. U.S.A. 109, 14802-14807.

Lewis, K., Arnott, W.P., Moosmüller, H., Chakrabarty, R.K., Carrico, C.M., 
Kreidenweis, S.M., Day, D.E., Malm, W.C., Laskin, A., Jimenez, J.L., Ulbrich, I.M., Huffman, J.A., Onasch, T.B., Trimborn, A., Liu, L., Mishchenko, M.I., 2009. Reduction in biomass burning aerosol light absorption upon humidification: roles of inorganically-induced hygroscopicity, particle collapse, and photoacoustic heat and mass transfer. Atmos. Chem. Phys. 9, 8949-8966.

Lewis, K., Arnott, W.P., Moosmuller, H., Wold, C.E., 2008. Strong spectral variation of biomass smoke light absorption and single scattering albedo observed with a novel dual-wavelength photoacoustic instrument. J. Geophys. Res. D: Atmos. 113, D16203.

Li, L., Chen, J., Chen, H., Yang, X., Tang, Y., Zhang, R., 2011. Monitoring optical properties of aerosols with cavity ring-down spectroscopy. J. Aerosol Sci 42, 277-284.

Li, L., Chen, J., Wang, L., Melluki, W., Zhou, H., 2013. Aerosol single scattering albedo affected by chemical composition: An investigation using CRDS combined with MARGA. Atmos. Res. 124, 149-157.

Li, W., Shao, L., 2010. Mixing and water-soluble characteristics of particulate organic compounds in individual urban aerosol particles. J. Geophys. Res. D: Atmos. 115, D02301.

Liu, L., Mishchenko, M.I., Patrick Arnott, W., 2008. A study of radiative properties of fractal soot aggregates using the superposition T-matrix method. J. Quant. Spectrosc. Radiat. Transfer 109, 2656-2663.

Mikhailov, E.F., Vlasenko, S.S., Podgorny, I.A., Ramanathan, V., Corrigan, C.E., 2006. Optical properties of soot-water drop agglomerates: An experimental study. J. Geophys. Res. D: Atmos. 111, D07209.

Moffet, R.C., Prather, K.A., 2009. In-situ measurements of the mixing state and optical properties of soot with implications for radiative forcing estimates. Proc. Nat. Acad. Sci. U.S.A. 106, 11872-11877.

Posfai, M., Anderson, J.R., Buseck, P.R., Sievering, H., 1999. Soot and sulfate aerosol particles in the remote marine troposphere. J. Geophys. Res. D: Atmos. 104, 21685-21693.

Qiu, C., Zhang, R.Y., 2012. Physiochemical properties of alkylaminium sulfates: hygroscopicity, thermostability, and density. Environ. Sci. Technol. 46, 4474-4480.

Ramanathan, V., Carmichael, G., 2008. Global and regional climate changes due to black carbon. Nat. Geosci. 1, 221-227.

Riemer, N., Vogel, H., Vogel, B., 2004. Soot aging time scales in polluted regions during day and night. Atmos. Chem. Phys. 4, 1885-1893.

Schnaiter, M., Gimmler, M., Llamas, I., Linke, C., Jäger, C., Mutschke, H., 2006. Strong spectral dependence of light absorption by organic carbon particles formed by propane combustion. Atmos. Chem. Phys. 6, 2981-2990.

Schnaiter, M., Horvath, H., Mohler, O., Naumann, K.H., Saathoff, H., Schock, O.W., 2003. UV-VIS-NIR spectral optical properties of soot and soot-containing aerosols. J. 
Schnaiter, M., Linke, C., Mohler, O., Naumann, K.H., Saathoff, H., Wagner, R., Schurath, U., Wehner, B., 2005. Absorption amplification of black carbon internally mixed with secondary organic aerosol. J. Geophys. Res. D: Atmos. 110, D19204.

Schwarz, J.P., Spackman, J.R., Fahey, D.W., Gao, R.S., Lohmann, U., Stier, P., Watts, L.A., Thomson, D.S., Lack, D.A., Pfister, L., Mahoney, M.J., Baumgardner, D., Wilson, J.C., Reeves, J.M., 2008. Coatings and their enhancement of black carbon light absorption in the tropical atmosphere. J. Geophys. Res. D: Atmos. 113.

Seinfeld, J.H., Pandis, S.N., 2006. Atmospheric Chemistry and Physics: From Air Pollution to Climate Change, 2nd Edition, pp. 384-388.

Shiraiwa, M., Kondo, Y., Iwamoto, T., Kita, K., 2010. Amplification of light absorption of black carbon by organic coating. Aerosol. Sci. Technol. 44, 46-54.

Slowik, J.G., Cross, E.S., Han, J.-H., Kolucki, J., Davidovits, P., Williams, L.R., Onasch, T.B., Jayne, J.T., Kolb, C.E., Worsnop, D.R., 2007. Measurements of Morphology Changes of Fractal Soot Particles using Coating and Denuding Experiments: Implications for Optical Absorption and Atmospheric Lifetime. Aerosol Sci. Technol. 41, 734-750.

Slowik, J.G., Stainken, K., Davidovits, P., Williams, L.R., Jayne, J.T., Kolb, C.E., Worsnop, D.R., Rudich, Y., DeCarlo, P.F., Jimenez, J.L., 2004. Particle Morphology and Density Characterization by Combined Mobility and Aerodynamic Diameter Measurements. Part 2: Application to Combustion-Generated Soot Aerosols as a Function of Fuel Equivalence Ratio. Aerosol Sci. Technol. 38, 1206-1222.

Stratmann, F., Bilde, M., Dusek, U., Frank, G.P., Hennig, T., Henning, S., Kiendler-Scharr, A., Kiselev, A., Kristensson, A., Lieberwirth, I., Mentel, T.F., Poschl, U., Rose, D., Schneider, J., Snider, J.R., Tillmann, R., Walter, S., Wex, H., 2010. Examination of laboratory-generated coated soot particles: An overview of the LACIS Experiment in November (LExNo) campaign. J. Geophys. Res. D: Atmos. 115, D11203.

Tang, I.N., Munkelwitz, H.R., 1994. Water activities, densities, and refractive indices of aqueous sulfates and sodium nitrate droplets of atmospheric importance. J. Geophys. Res. D: Atmos. 99, 18801-18808.

Wang, L., Khalizov, A.F., Zheng, J., Xu, W., Ma, Y., Lal, V., Zhang, R., 2010. Atmospheric nanoparticles formed from heterogeneous reactions of organics. Nature Geosci 3, 238-242.

Zhang, R.Y., Khalizov, A.F., Pagels, J., Zhang, D., Xue, H.X., McMurry, P.H., 2008. Variability in morphology, hygroscopicity, and optical properties of soot aerosols during atmospheric processing. Proc. Nat. Acad. Sci. U.S.A. 105, 10291-10296. 
638 Fig. 1. Optical properties of BC-BrC. (a) scattering and absorption cross sections, and 639 single scattering albedo (SSA) of BC-BrC, BC-BrC-SA, BC-BrC-SA-AM, 640 BC-BrC-SA-TEA particles at $5 \%$ and $85 \% \mathrm{RH}$, respectively. The error bars represent 641 one standard deviations $(\sigma)$. The open circles represent direct measurement, while the 642 solid circles are corrected from $78 \%$ to $85 \%$ RH. (b) Absorption enhancement ( $\left.\mathrm{E}_{\mathrm{abs}}\right)$ 643 as a function of $\mathrm{RH}$ and $\mathrm{R}_{\mathrm{BC}-\mathrm{BrC}}$.

a

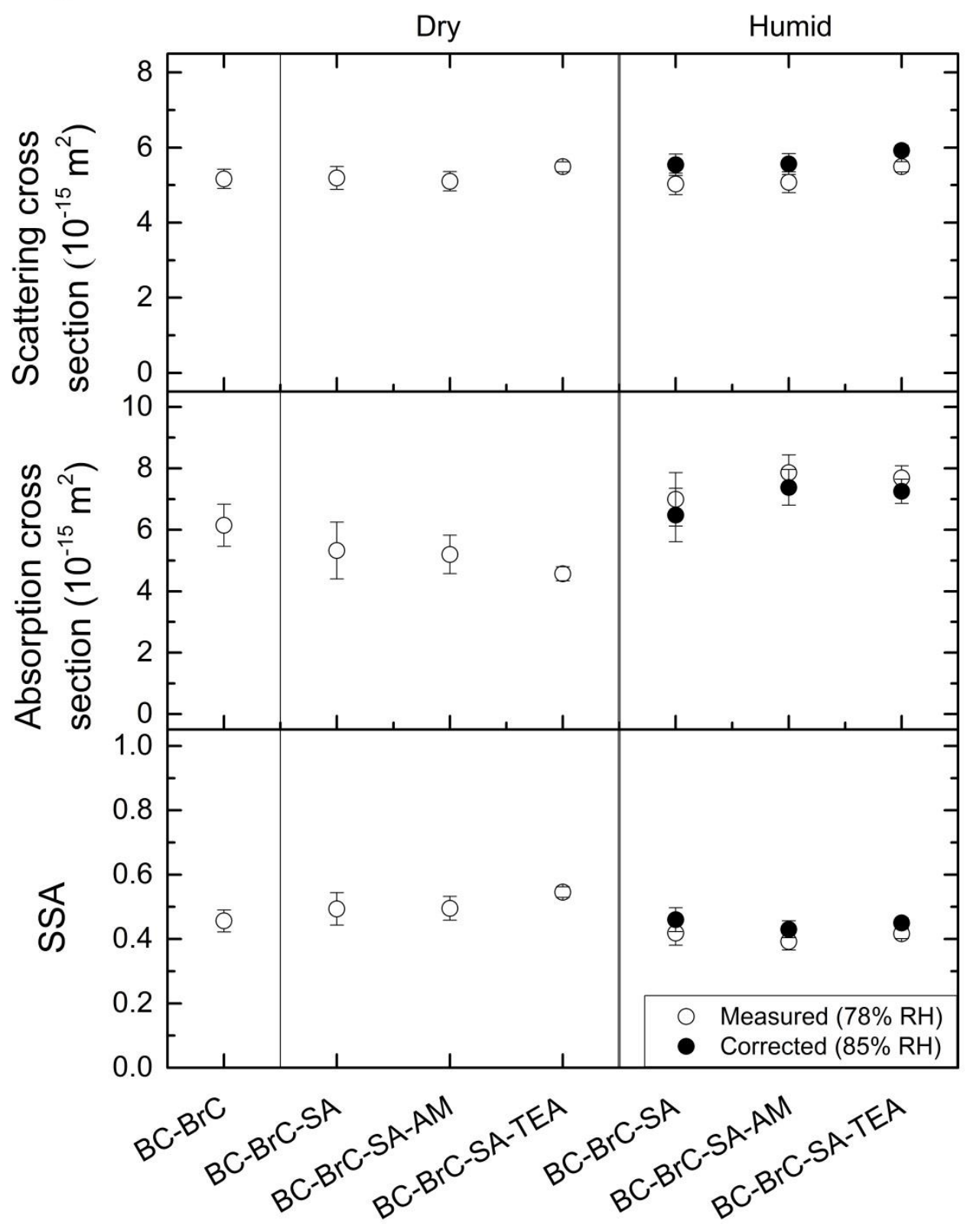




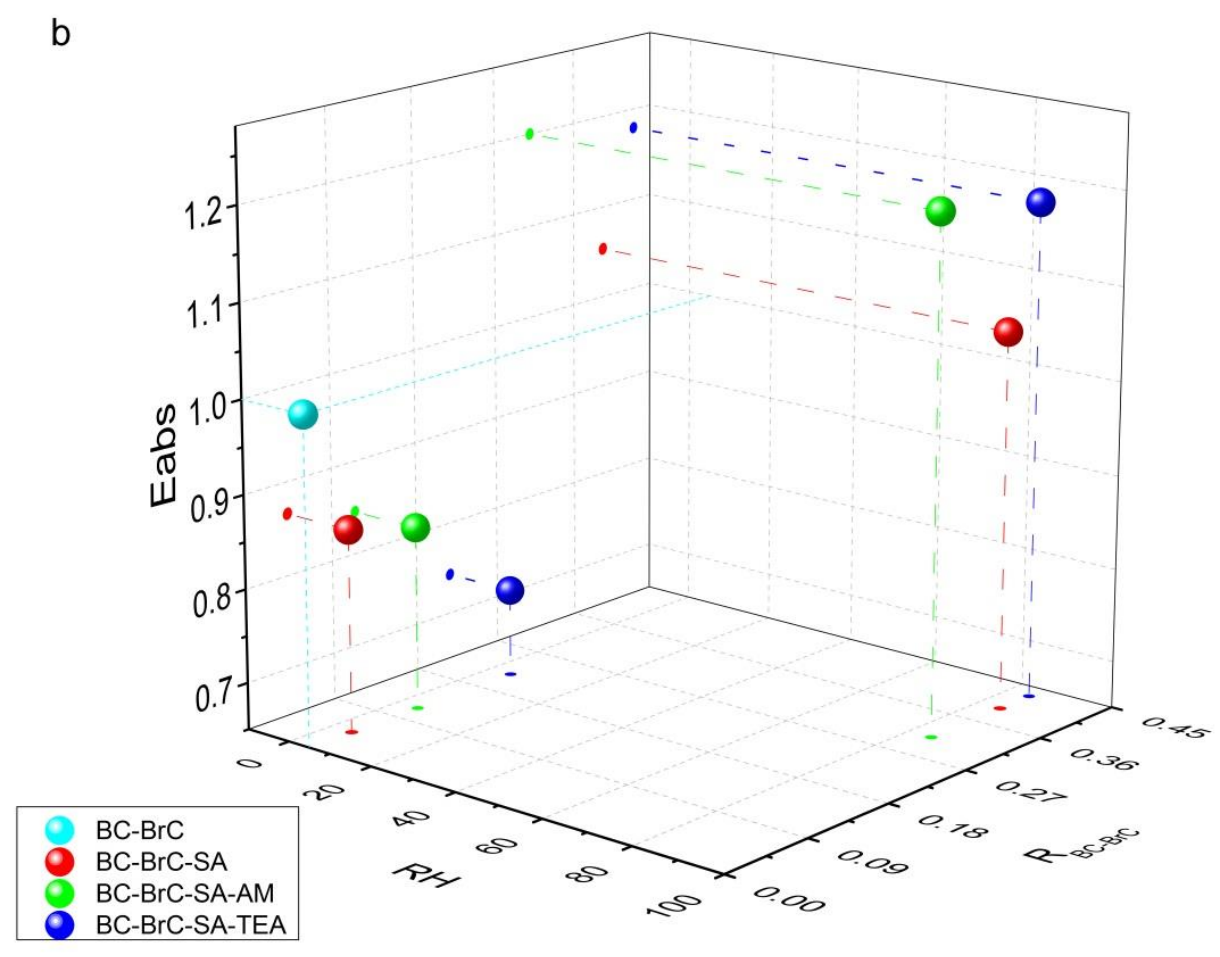

646

647

648 Fig. 2. TEM images of different types of BC-BrC: (a) embedded/heavily coated fresh $649 \mathrm{BC}-\mathrm{BrC}$ that represented the majority of collected particles; (b) partially coated chain 650 agglomerates that were a minor fraction of collected particles; (c) BC-BrC-SA; (d) 651 BC-BrC-SA-AM; (e) BC-BrC-SA-TEA. EDX spectra of (f) BC-BrC-SA and (g) 652 BC-BrC-SA-AM. BC-BrC-SA-AM particles were exposed to $85 \% \mathrm{RH}$ before 653 collection, while other particles were sampled at 5\% RH.

654
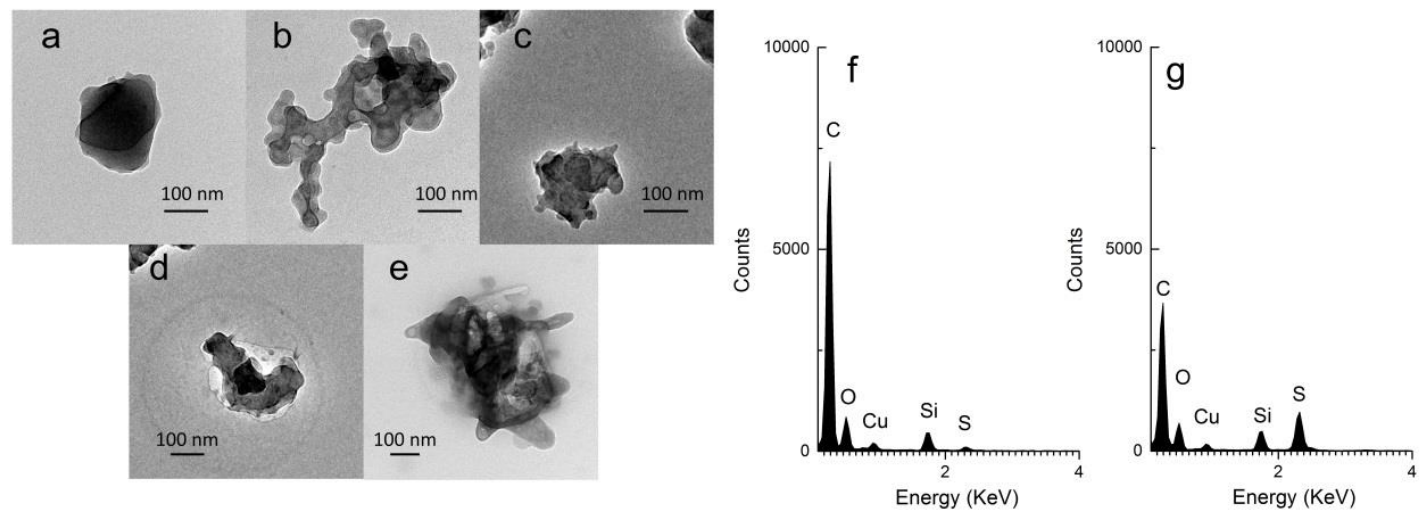
657

658

659

660

661

662

663

664

665

Fig. 3. Hygroscopic growth factor $\left(\mathrm{G}_{\mathrm{f}}\right)$ of 150-nm BC-BrC. (a), SA, upon condensation of $\mathrm{H}_{2} \mathrm{SO}_{4}$; (b), SA-AM, exposure of $\mathrm{H}_{2} \mathrm{SO}_{4}$-coated $\mathrm{BC}-\mathrm{BrC}$ with $\mathrm{NH}_{3}$; (c), SA-TEA, exposure of $\mathrm{H}_{2} \mathrm{SO}_{4}$-coated $\mathrm{BC}-\mathrm{BrC}$ with $\left(\mathrm{CH}_{3} \mathrm{CH}_{2}\right)_{3} \mathrm{~N}$.

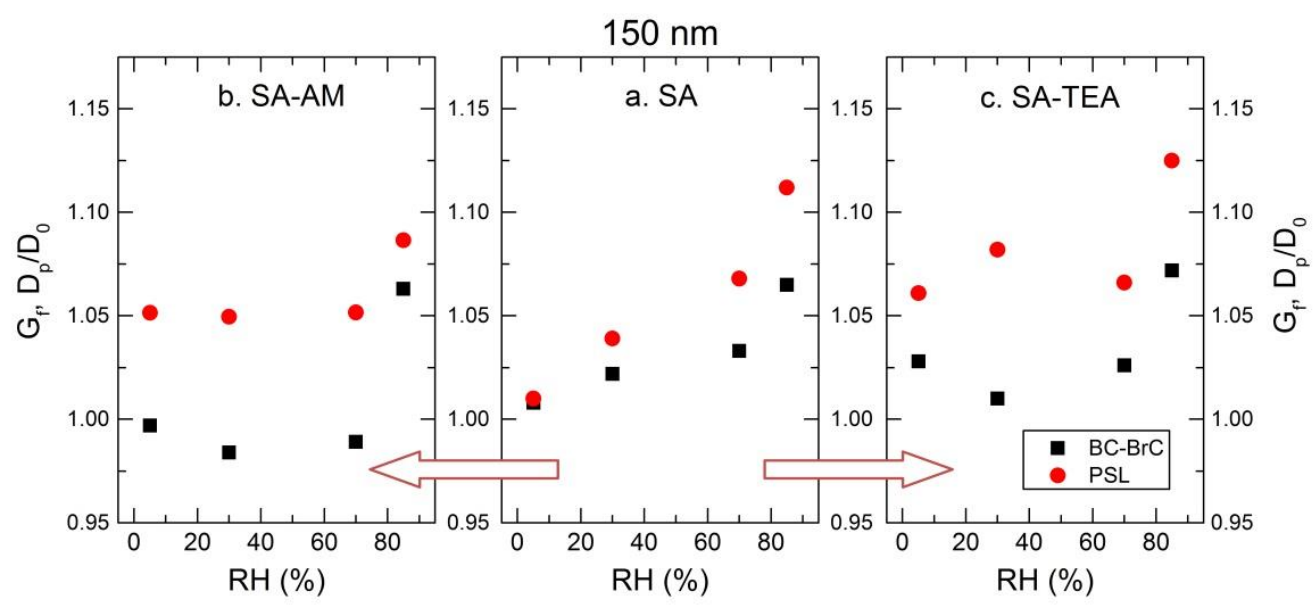

Fig. 4. Shrink in size $\left(D_{p, 250^{\circ} \mathrm{C}} / D_{0}\right)$ measured by DMA-TD-DMA at $250^{\circ} \mathrm{C}$. The TD was set at $250^{\circ} \mathrm{C}$ to allow complete evaporation of non-refractory components. For high RH experiments, a humidifier was placed between the first DMA and TD to elevate RH up to $85 \%$.

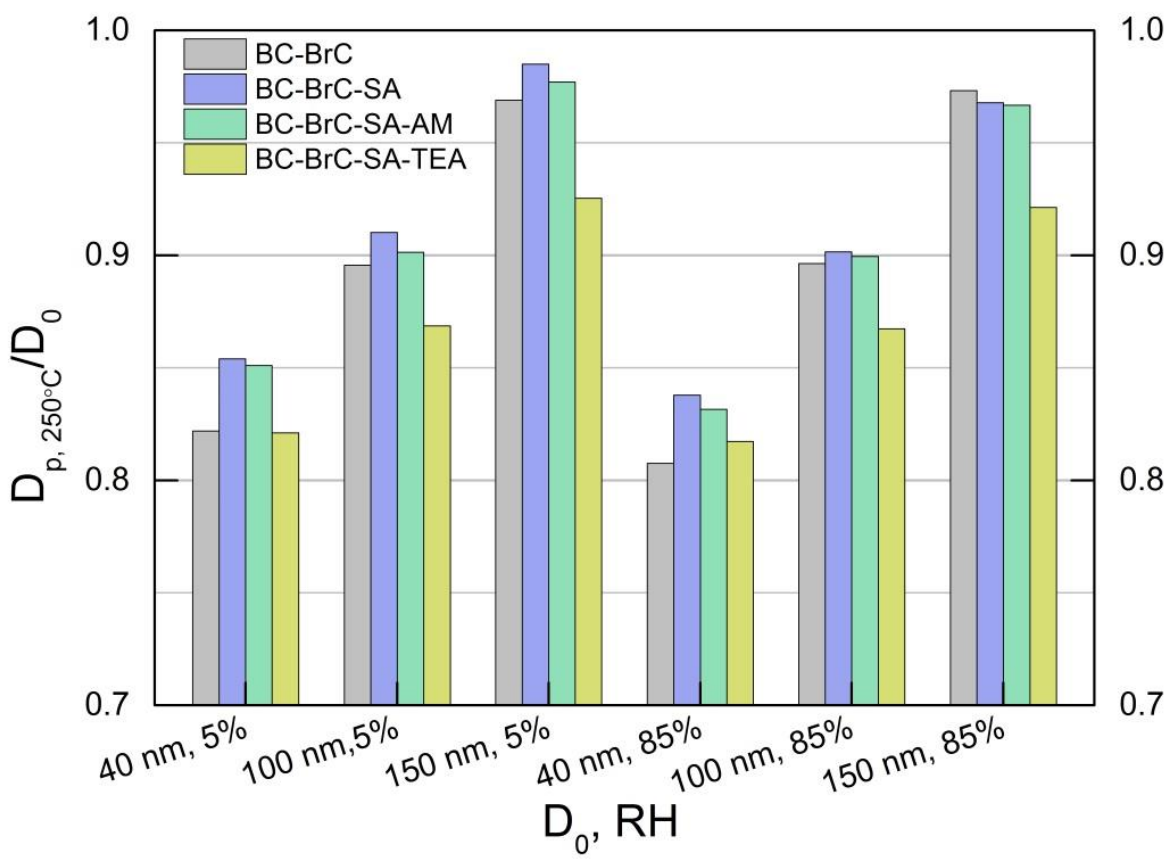


Fig. 5. $\mathrm{E}_{\mathrm{abs}}$ for processed $\mathrm{BC}-\mathrm{BrC}$ under dry (dash line) or wet (solid line) conditions calculated using Mie theory, and experimentally observed $\mathrm{E}_{\mathrm{abs}}$ for BC-BrC-SA (black squares), BC-BrC -SA-AM (red squares) and BC-BrC-SA-TEA (green squares). The circles at the end of curves correspond to $\mathrm{R}_{\mathrm{BC}-\mathrm{BrC}}$ with $\sim 10$-fold sulfate ions of the experimental data in this study.

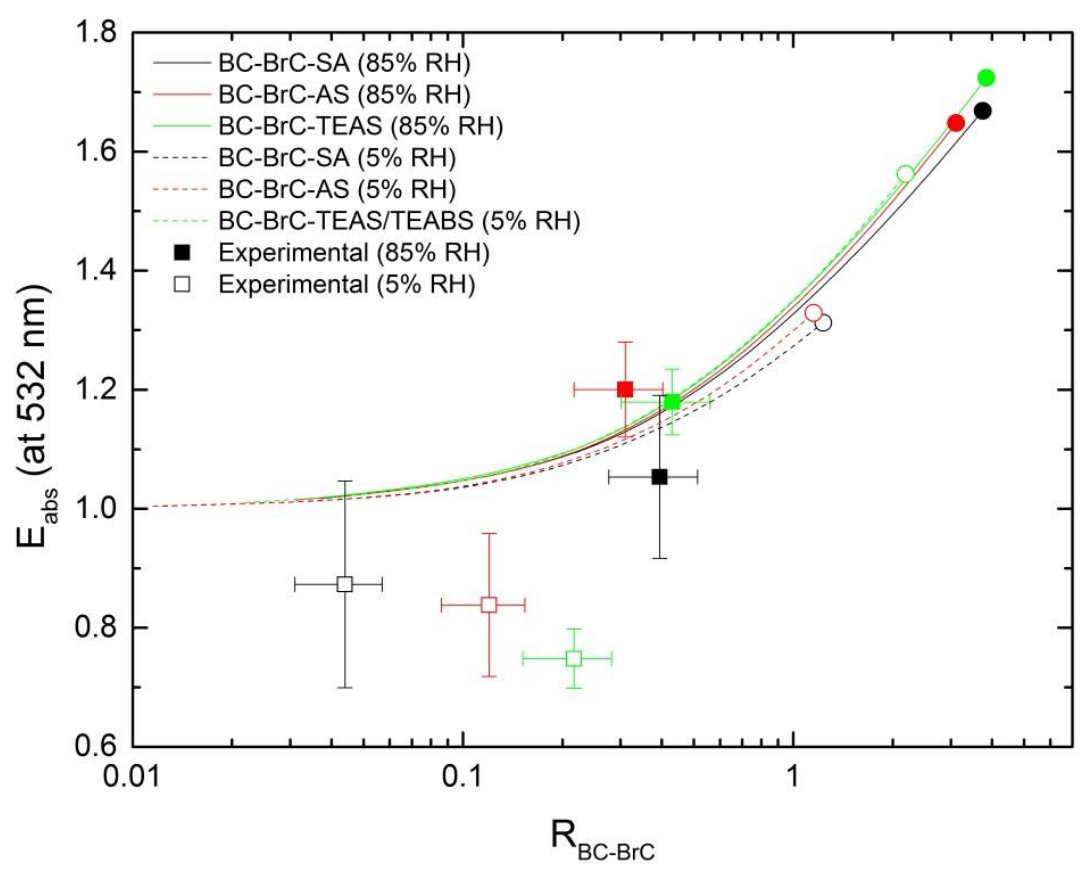

Fig.6. (a), Processing processes for generation of SA, SA-AM and SA-TEA coatings on BC-BrC or PSL particles. (b), Proposed mechanism for alteration in light absorption for internally mixed $\mathrm{BC}-\mathrm{BrC}$ upon surface reaction and hydration. The black aggregates represent refractory $\mathrm{BC}$ inclusion, and the gray and clear circles represent organic and inorganic materials, respectively. 
a.

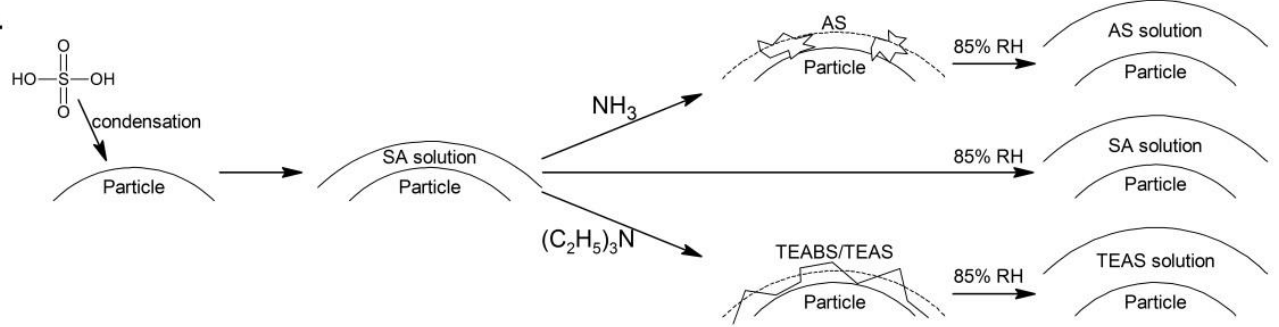

b.

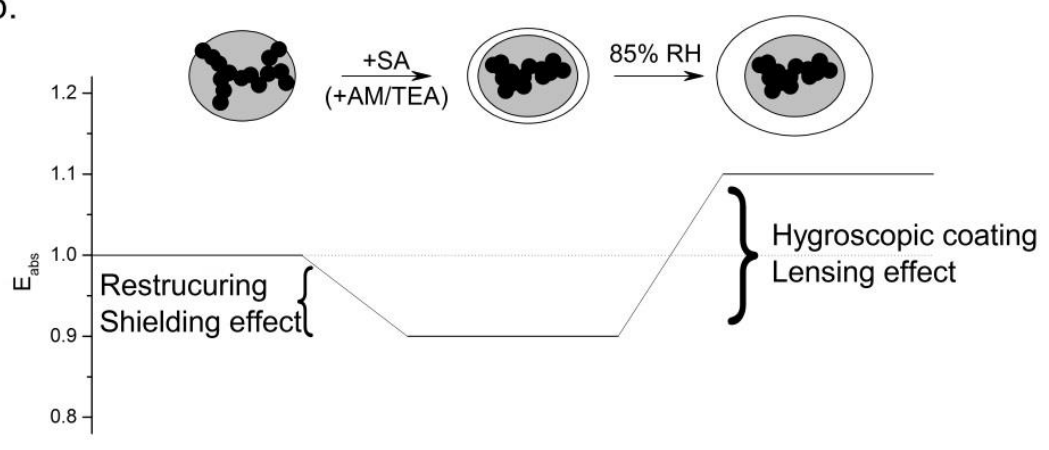

682

29 
Highlights:

- Condensation of $\mathrm{H}_{2} \mathrm{SO}_{4}$, surface neutralization reactions and subsequent hydration of $\mathrm{BC}-\mathrm{BrC}$ particles have been simulated.

- Restructuring of $\mathrm{BC}-\mathrm{BrC}$ particles due to surface neutralization reactions causes reduction in light absorption at low relative humidity.

- Hygroscopic growth of processed $\mathrm{BC}-\mathrm{BrC}$ particles enhances light absorption at high relative humidity. 


\section{Supplementary Information}

for

\section{Modification in light absorption cross section of laboratory- generated Black Carbon-Brown Carbon particles upon surface reaction and hydration}

Hui Chen ${ }^{\mathrm{a}, \mathrm{b}, \mathrm{c}}$, Dawei Hu${ }^{\mathrm{a}, \mathrm{b}}$, Lin Wang ${ }^{\mathrm{a}, \mathrm{d} *}$, Abdelwahid Mellouki ${ }^{\mathrm{b}, \mathrm{c}}$, Jianmin Chen $^{\mathrm{a}, \mathrm{d} *}$

${ }^{a}$ Shanghai Key Laboratory of Atmospheric Particle Pollution and Prevention, Department of Environmental Science \& Engineering, Fudan University, 220 Handan Road, Shanghai 200433, China

${ }^{b}$ Institut de Combustion, Aérothermique, Réactivité et Environnement,Centre Nationaldela Recherche Scientifique(ICARE-CNRS), 1C, Avenue de la Recherche Scientifique,45071 Orléans cedex 02,France

${ }^{c}$ Observatoire des Sciences de l'Univers en Région Centre(OSUC)-Université d'Orléans, $1 \mathrm{~A}$ rue de la Férollerie 45071 Orléans cedex 02,France

${ }^{d}$ Fudan Tyndall Centre, Fudan University, 220 Handan Road, Shanghai 200433, China

*Corresponding authors: Lin Wang, lin_wang@fudan.edu.cn +86 21 65643568; Jianmin Chen, jmchen@fudan.edu.cn,+862165642298 
1. Experimental setup

Supplementary Scheme. Schematic layout of BC-BrC generator and the tandem DMA setup in coupled with aerosol particle mass (APM) analyzer, low pressure impactor (LPI), cavity ring-down spectrometer (CRDS), and nephelometer. The two DMAs were performed by a "open loop" setting, whose inlets and outlets of sheath flow were controlled by mass flow controllers (MFC) and orifices respectively. Condensation particle counter (CPC) provided a constant sample flow rate of 1.0 LPM in all applications. Extended exposure of $\mathrm{BC}-\mathrm{BrC}$ or PSL to sulfuric acid vapor was carried out in the first residence chamber (RC 1), and excess sulfuric acid was eliminated by a $\mathrm{KOH}$ trap. Ammonia $\left(\mathrm{NH}_{3}\right)$ or triethylamine $\left(\left(\mathrm{C}_{2} \mathrm{H}_{5}\right)_{3} \mathrm{~N}\right)$ was introduced downstream to interact with $\mathrm{H}_{2} \mathrm{SO}_{4}$-coated particles. While a 10cm-long and 6-mm-i.d. tubing worked for $\mathrm{NH}_{3}$ experiments, a $100 \mathrm{ml}$ residence chamber (RC 2) was used for $\left(\mathrm{C}_{2} \mathrm{H}_{5}\right)_{3} \mathrm{~N}$ experiments.

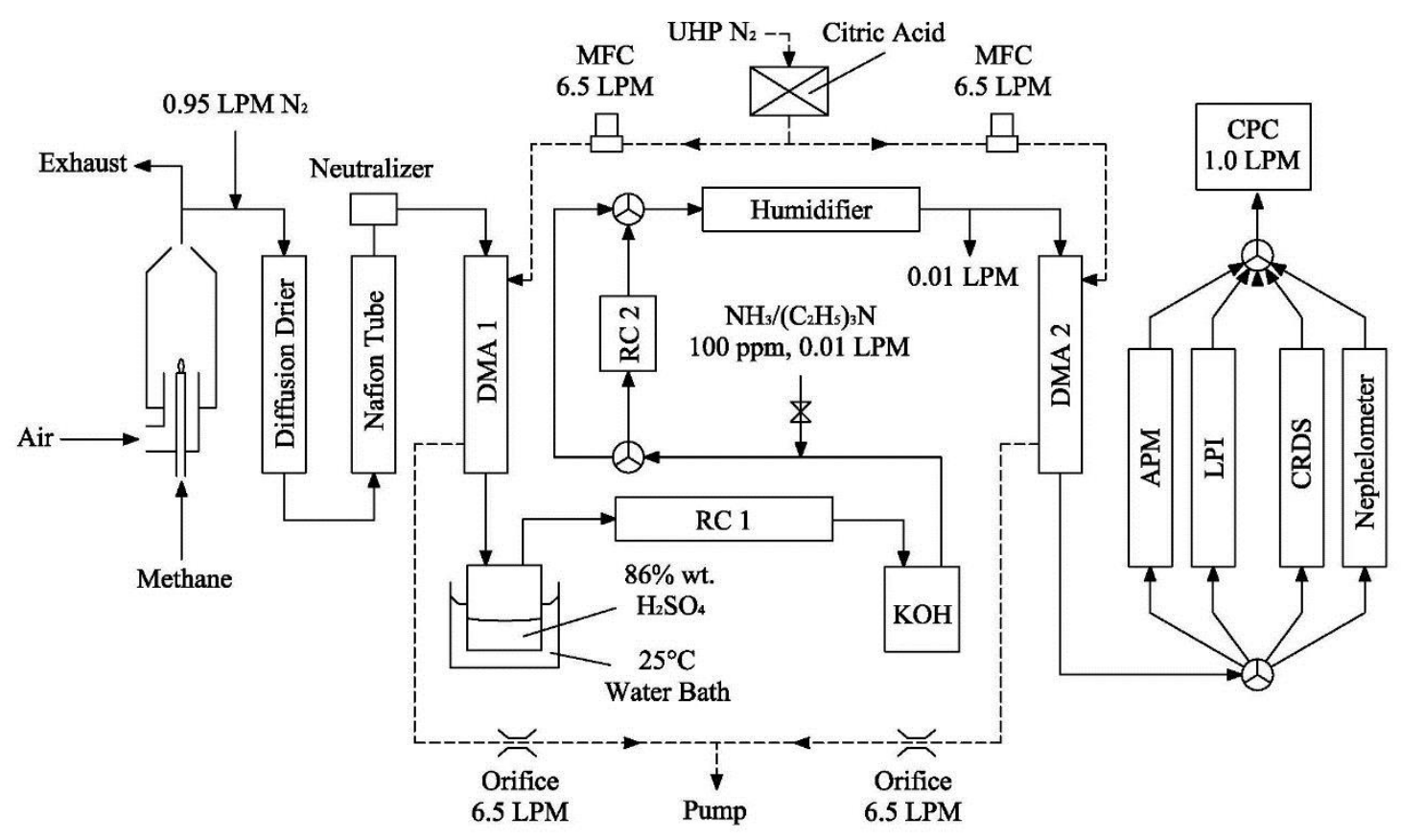




\section{BC-BrC particle characterization}

Supplementary Figure S1. Size distribution of a polydisperse fresh BC-BrC population. It was characterized by a count median diameter of $69 \mathrm{~nm}$ and a geometric standard deviation of 1.24.

The fraction of doubly charged particles was estimated based on the particle size distribution and the bipolar charge distribution (Wiedensohler, 1988). The charge efficiency for singly charged $150 \mathrm{~nm}$ and doubly charged $225 \mathrm{~nm}$ particles is predicted to be $23 \%$ and $8 \%$, respectively (Wiedensohler, 1988). On the other hand, the particle size distribution showed a very narrow peak shape with a median diameter at $69 \mathrm{~nm}$ and a geometric standard deviation of 1.24 . We benefit from the narrow size distribution so that the ratio of number concentration of $150 \mathrm{~nm}$ and $225 \mathrm{~nm}$ particles was 23:1. Hence, doubly charged particle with a diameter of $225 \mathrm{~nm}$ contributed $\sim 1 \%$ to singly charged particle with a diameter of $150 \mathrm{~nm}$ classified by DMA. This would lead to an overestimation of $7 \%$ and $3 \%$ for scattering and absorption coefficients for singly charged BCBrC particles according to $\sigma_{\text {scat }} \propto D_{p}^{5}$ and $\sigma_{a b s} \propto D_{p}^{3}$, respectively, assuming an identical refractive index for $150 \mathrm{~nm}$ and $225 \mathrm{~nm} \mathrm{BC-BrC}$.

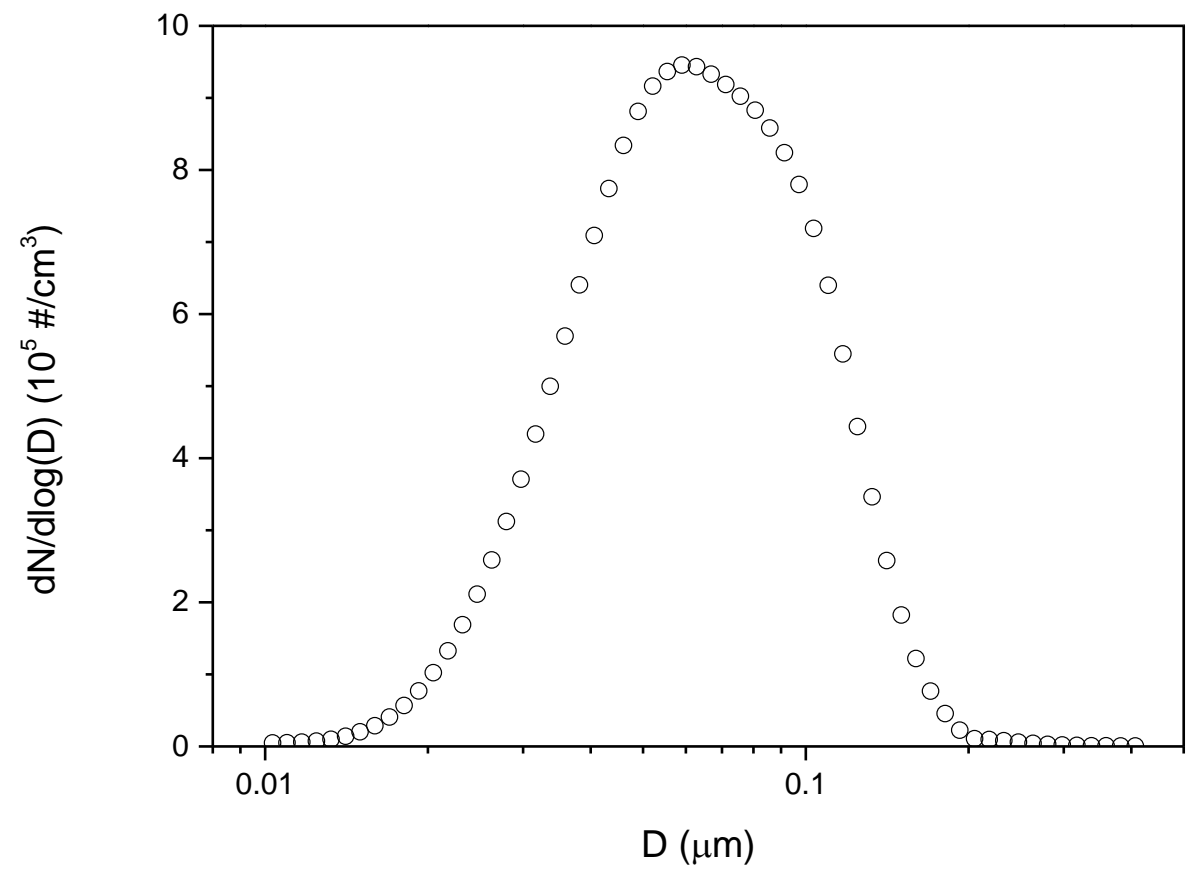


Supplementary Figure S2. UV-Vis spectra of BC-BrC in dichloromethane $\left(\mathrm{CH}_{2} \mathrm{Cl}_{2}, \mathrm{HPLC}\right.$ grade) emulsion. UV-Vis spectra of three polycyclic aromatic hydrocarbons (PAHs, acenaphthylene, chrysene and fluoranthene) detected by GC-MS are plotted as references (Linstrom and Mallard, 2014).

The $\mathrm{BC}-\mathrm{BrC}$ particles were deposited on a glass slide placed above the chimney exhaust, and then were dissolved and/or dispersed by placing the glass slide into dichloromethane in an ultrasonic bath for $30 \mathrm{~min}$. The light attenuation of the emulsion was measured by a photodiode array spectrophotometer (Scinco s-3150). An extinction Ångström exponent (EAE) of 2.9 was derived from the light attenuation in the wavelength range of 250-800 nm.

The obtained light attenuation should be assigned to light extinction because scattering of suspended $\mathrm{BC}$ in dichloromethane also contributed. Hence, the light attenuation should be considered as a sum of light absorption by dissolved OC (mostly PAHs up to 600 Da molecule weight) (Michela et al., 2008) and extinction by dispersed BC primary spheres.

A Mie theory calculation using a volume equivalent diameter of $100 \mathrm{~nm}$ and a complex refractive index of 1.22+0.31i yielded an extinction Angström exponent of $\sim 1.05$. The complex refractive index was the refractive index of $\mathrm{BC}$ as $1.74+0.44 \mathrm{i}$ (Bond and Bergstrom, 2006) normalized by that of dichloromethane as $1.424+0.00 \mathrm{i}$. If the $\mathrm{BC}$ particles break up into primary spheres with a smaller size (e.g., $20 \mathrm{~nm}$ ), the EAE can be equal to unity. Therefore, we draw the conclusion that an EAE of 2.9 suggests the presence of $\mathrm{BrC}$, in line with the GC-MS analysis.

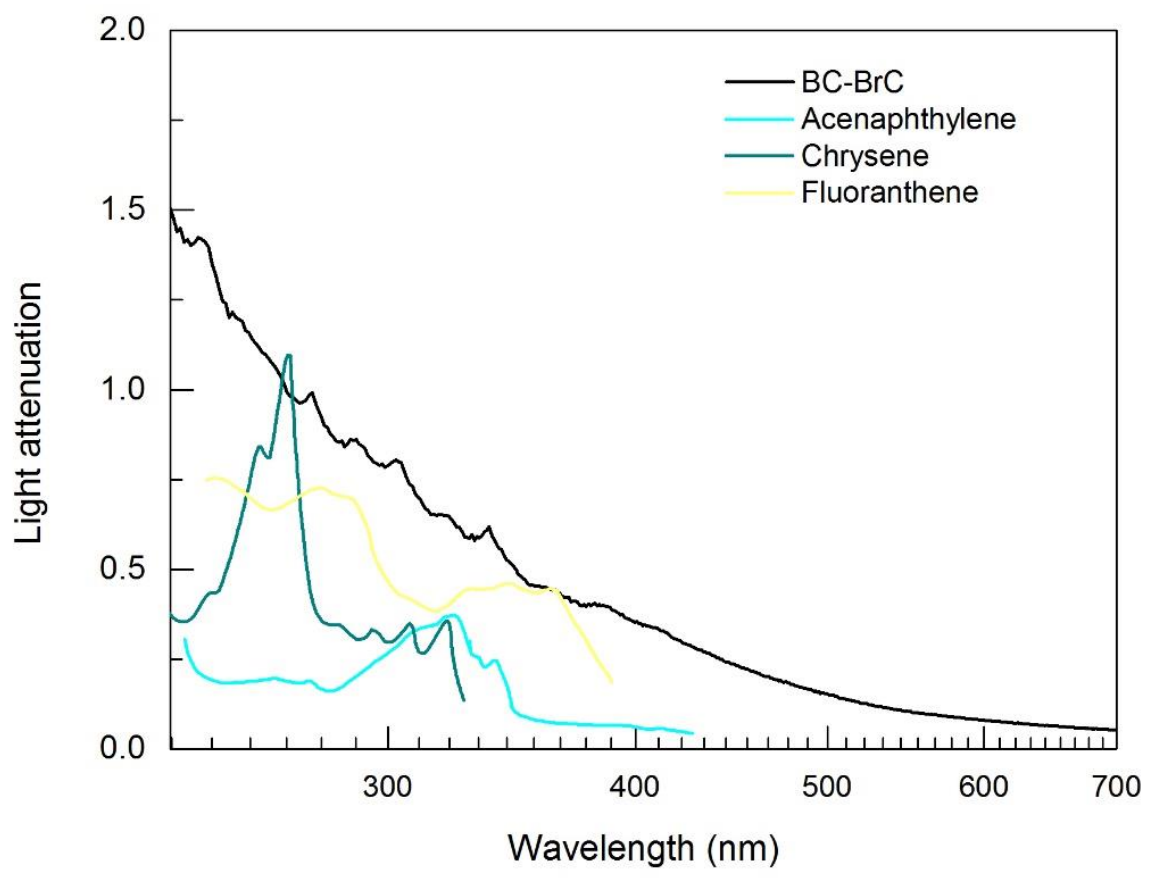


Supplementary Figure S3. GC-MS analysis of chemical composition of BC-BrC.

The emulsion of deposited $\mathrm{BC}-\mathrm{BrC}$ was sonicated for $10 \mathrm{~min}$ and filtered, and $\mathrm{CH}_{2} \mathrm{Cl}_{2}-\mathrm{Soluble}$ organic components were analyzed using an Agilent 6890 series GC system with a HP-5 MS capillary column $(30 \mathrm{~m} \times 0.32 \mathrm{~mm} \times 0.25 \mu \mathrm{m})$, coupled to a HP 5973 mass selective detector. The $\mathrm{CH}_{2} \mathrm{Cl}_{2}$ extracts indicates the presence of a series of PAHs including acenaphthylene, fluoranthene, pyrene, cyclopenta[cd]pyrene, chrysene, benzo[K]fluoranthene, and benzo[a]pyrene.

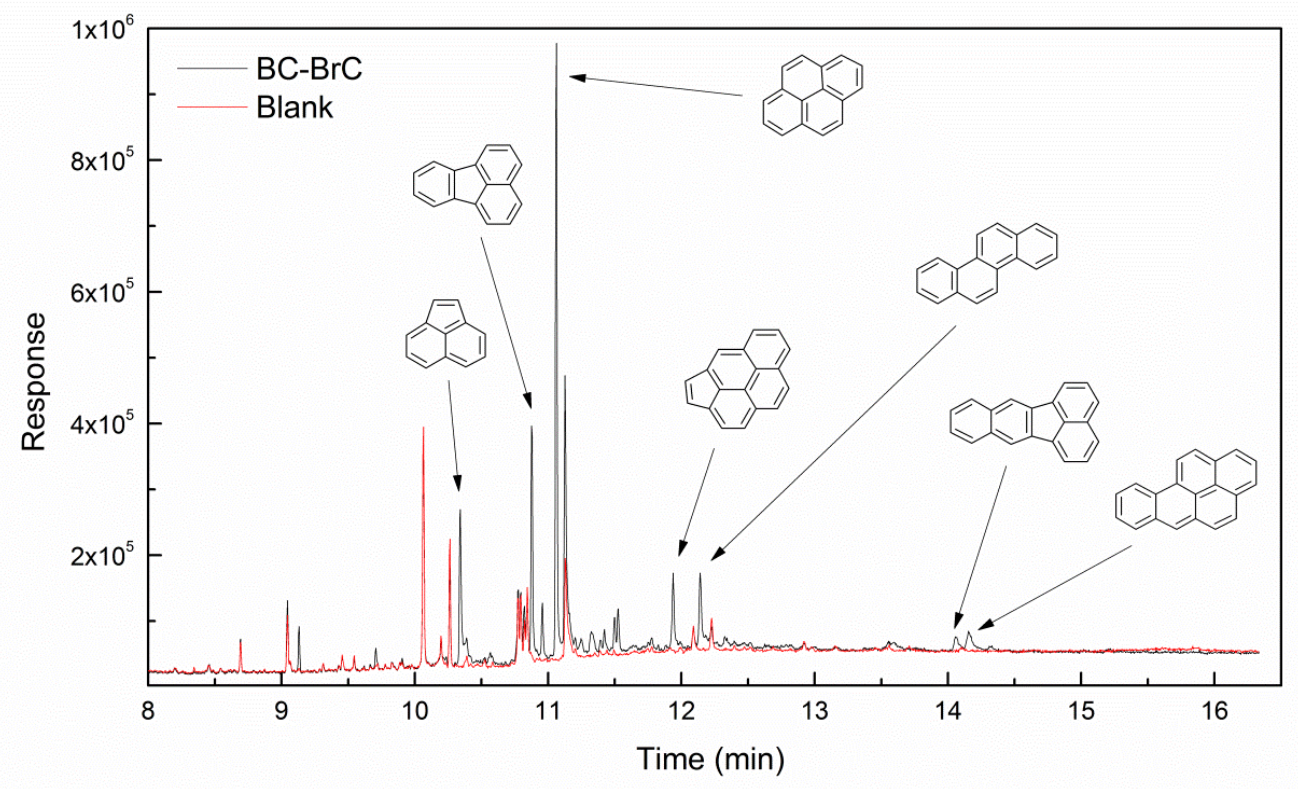




\section{Scattering Ångström exponents}

Scattering Ångström exponents of fresh and processed BC-BrC with an initial diameter of 150 $\mathrm{nm}$ ranged from 3.43 to 3.56. Since scattering Ångström exponents are largely determined by the particle size, no significant alteration was observed for fresh and processed $\mathrm{BC}-\mathrm{BrC}$ upon surface reaction and hydration. In addition, inter-comparison between our measurement and theoretical calculation has been performed. For $150 \mathrm{~nm}$ PSL particles with a complex radiative index of $1.598+0.00 \mathrm{i}$, the measured Ångstrom scattering coefficient in the $450-700 \mathrm{~nm}$ wavelength range by a nephelometer was 3.76 , in good agreement with the theoretical prediction of 3.75

Supplementary Table S1. Scattering Ångström exponents of fresh and processed BC-BrC and authentic PSL.

\begin{tabular}{lll}
\hline & $5 \% \mathrm{RH}$ & $85 \% \mathrm{RH}$ \\
\hline BC-BrC & 3.56 & \\
BC-BrC-SA & 3.53 & 3.52 \\
BC-BrC-SA-AM & 3.45 & 3.53 \\
BC-BrC-SA-TEA & 3.44 & 3.43 \\
PSL & 3.76 & \\
\hline
\end{tabular}




\section{Uncertainty analysis}

The CRDS system measured the extinction coefficient of aerosol particles with an uncertainty of 3\% under laboratory experimental conditions ( $\mathrm{Li}$ et al., 2011). Following the procedures recommended by Anderson and Ogren (1998), the precision uncertainty for scattering coefficient measurement using nephelometer (TSI, 3563) during our experiment was within 1\%, while the accuracy was within 7\%. Therefore, the uncertainty of absorption coefficient and single scattering albedo (SSA) was estimated to be $7 \%-9 \%$ and $8 \%$, respectively, according to the following equations:

$$
\begin{aligned}
& \frac{\Delta \sigma_{a b s}}{\sigma_{a b s}}=\sqrt{\left(\Delta \sigma_{e x t}\right)^{2}+\left(\Delta \sigma_{\text {scat }}\right)^{2}} \\
& \frac{\Delta S S A}{S S A}=\sqrt{\left(\frac{\Delta \sigma_{e x t}}{\sigma_{e x t}}\right)^{2}+\left(\frac{\Delta \sigma_{s c a t}}{\sigma_{\text {scat }}}\right)^{2}}
\end{aligned}
$$

where $\Delta \sigma_{a b s}, \Delta \sigma_{e x t}, \Delta \sigma_{\text {scat }}$ and $\Delta S S A$ are one standard deviation of absorption coefficient, extinction coefficient, scattering coefficient and single scattering albedo, respectively. Note that the uncertainty of absorption/scattering/extinction cross sections partially originated from the fluctuation of particle concentration monitored by CPC.

$$
\frac{\Delta C_{a b s / s c a t / e x t}}{C_{a b s / s c a t / e x t}}=\sqrt{\left(\frac{\Delta \sigma_{a b s / s c a t / e x t}}{\sigma_{a b s / s c a t / e x t}}\right)^{2}+\left(\frac{\Delta N}{N}\right)^{2}}
$$

where $\Delta C_{a b s / s c a t / e x t}$ is the uncertainty of absorption/scattering/extinction cross section and $\Delta N$ represents one standard deviation of the particle concentration. 


\section{5. $R_{B C-B r C}$}

We define $R_{B C-B r C}$ as the ratio between the mass of nonrefractory inorganic coatings $\left(m_{N R-I}\right)$ and the mass of $\mathrm{BC}-\mathrm{BrC}$ particle $\left(m_{B C-B r C}\right)$ :

$$
R_{B C-B r C}=\frac{m_{N R-I}}{m_{B C-B r C}}=\frac{\pi \rho_{e f f} \times D_{0}^{3} \times\left(G_{f}^{3}-1\right)}{6 m_{B C-B r C}}
$$

where $\rho_{\text {eff }}$ is the effective density of the nonrefractory coating, $D_{0}$ is the initial particle diameter, $G_{f}$ is the measured growth factor using TDMA.

Supplementary Table S2. Mass and densities of the nonrefractory coating, and $R_{B C-B r C}$.

\begin{tabular}{lllll}
\hline & $\mathrm{RH}$ & $\rho_{\text {eff }}\left(\mathrm{g} / \mathrm{cm}^{3}\right)^{*}$ & $m_{N R-I}(\mathrm{fg})$ & $R_{B C-B r C}$ \\
\hline BC-BrC-SA & $5 \%$ & 1.60 & 0.09 & 0.04 \\
BC-BrC-SA-AM & $5 \%$ & 0.77 & 0.22 & 0.11 \\
BC-BrC-SA-TEA & $5 \%$ & 1.23 & 0.42 & 0.22 \\
BC-BrC-SA & $85 \%$ & 1.16 & 0.77 & 0.39 \\
BC-BrC-SA-AM & $85 \%$ & 1.21 & 0.60 & 0.31 \\
BC-BrC-SA-TEA & $85 \%$ & 1.12 & 0.84 & 0.43
\end{tabular}

* $\rho_{\text {eff }}$ is determined by the physicochemical properties of nonrefractory coating dependent on their chemical composition and morphology (see Supplementary Tables 3a and 3b). 


\section{Hygroscopicity of processed particles}

Supplementary Figure S4. Hygroscopic growth factors $\left(G_{f}\right)$ for BC-BrC (square) and PSL (circle) with initial diameter of (a) $40 \mathrm{~nm}$ and (b) $100 \mathrm{~nm}$ for three different sulfate coatings: SA, SA-AM and SA-TEA.
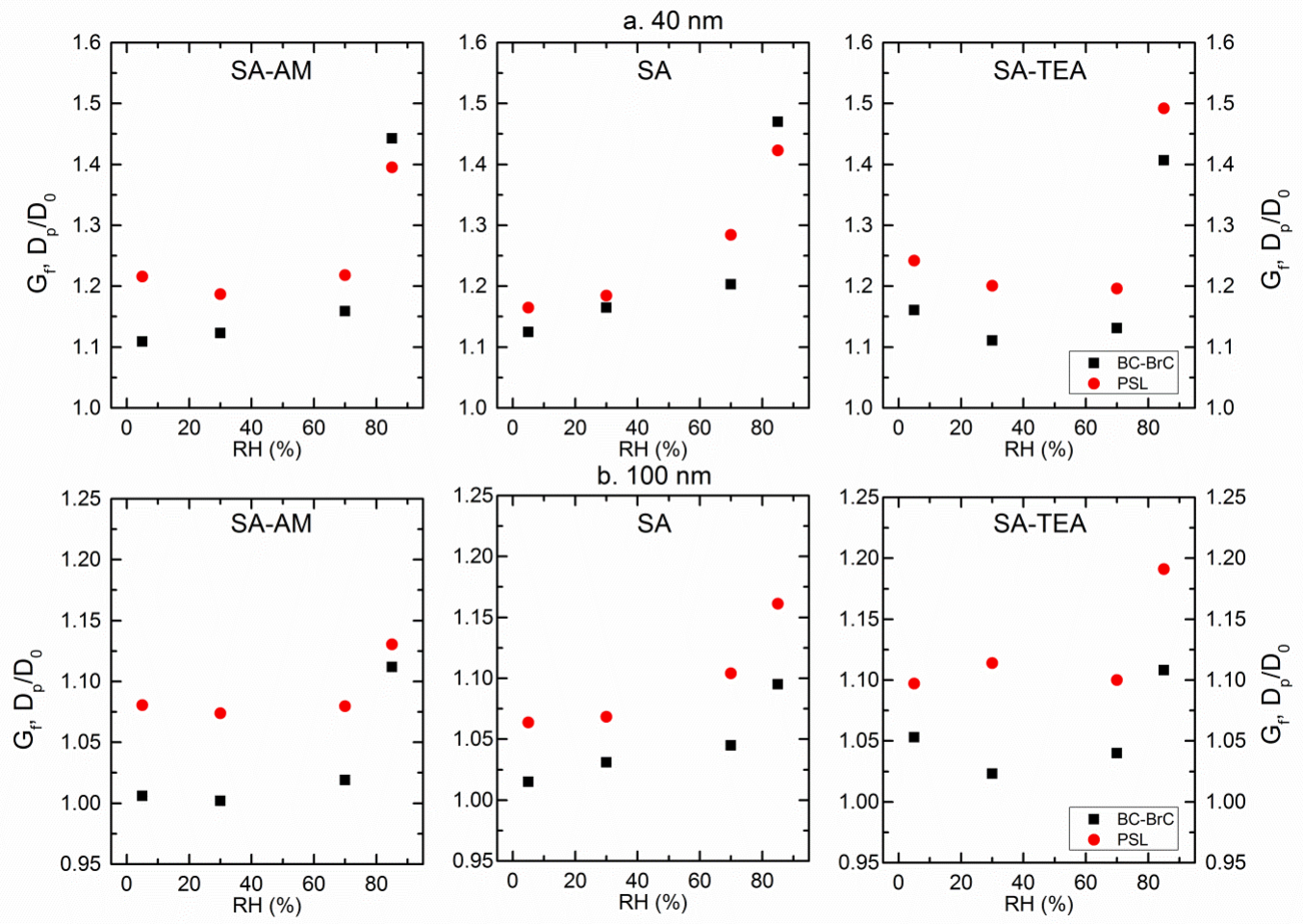
7. Moles of sulfuric ions $\left(\mathrm{SO}_{4}^{2-}\right)$ and effective density $\rho_{\text {eff }}$

The moles of $\mathrm{SO}_{4}^{2-}$ at variable relative humidity have been derived from $G_{f}$ for PSL-SA and PSL-SA-AM and physicochemical properties of corresponding compounds.

mole $_{S O_{4}^{2-}, R H}=\frac{\pi \rho_{R H} \times w t_{R H} \times D_{0}^{3} \times\left(G_{f, R H}^{3}-1\right)}{6 M_{s}}$

where $\rho_{R H}$ is the density of solution, $w t_{R H}$ is the weight percentage of solute, and $M_{s}$ is the molar mass of solute. $\rho_{R H}$ and $w t_{R H}$ are calculated from the method recommended by Biskos et al. (2009) and E-AIM (http://www.aim.env.uea.ac.uk, Wexler and Clegg (2002)).

The calculated results exhibited good agreement among PSL-SA at the RH range of 30-85\% and PSL-SA-AM at $85 \% \mathrm{RH}$, which suggested no sulfuric acid loss or accumulation during the humidity elevation or neutralization processes (Table S3a). The derived moles of $\mathrm{SO}_{4}^{2-}$ for PSLSA at 5\% RH didn't agree well with the values at 30\%-85\% RH, which might be explained by the uncertainties in measuring $G_{f}$ when coating thickness was close to the detection limit of TDMA. Calculated molecules of $\mathrm{SO}_{4}^{2-}$ in the PSL-SA-AM coating at 5\%-70\% $\mathrm{RH}$ varied in a narrow range, but were higher than those in the solution coating. It inferred an overestimated coating volume (thickness) derived from the $G_{f}$ measurements, which can be rationalized by the formation of nonuniform solid crystalline of ammonium sulfate on the particle surface (Gibson et al., 2007). The effective densities ( $\rho_{\text {eff }}$ ) of those AS coating below deliquescence relative humidity were calculated by the equation:

$$
\rho_{e f f, A S}=\frac{6 M_{A S} \times \overline{\text { mole }_{S A}}}{\pi D_{0}^{3}\left(G_{f, R H}^{3}-1\right)}
$$

where $\overline{\text { mole }_{S A}}$ represents the average derived from data sets at $30 \%-85 \% \mathrm{RH}$ with $\pm 1 \sigma$ uncertainty.

The moles of $\mathrm{SO}_{4}^{2-}$ derived from PSL-SA-TEA as a triethylaminium sulfate (TEAS) solution at $85 \% \mathrm{RH}$ was identical to $\overline{\text { mole }_{S A}}$. However, the calculated moles of $\mathrm{SO}_{4}^{2-}$ for PSL-SA-TEA at $5 \%, 30 \%$ and $70 \%$ RH were generally smaller when physicochemical properties of TEAS used, which indicated that the PSL-SA was partially neutralized leading to the formation of a mixture of triethylaminium bisulfate/sulfate (TEASBS/TEAS) (Supplementary Fig. S5). Because the ethyl group terminal restricted the hygroscopic growth until 85\%, the physicochemical properties of TEABS or TEAS from solution (Clegg et al., 2013) are likely to be unsuitable at intermediate humidity environment in our study. 
Supplementary Table S3a. Moles of $\mathrm{SO}_{4}^{2-}$ calculated for PSL-SA and PSL-SA-AM.

\begin{tabular}{|c|c|c|c|c|c|c|c|}
\hline & RH & $\begin{array}{r}D_{0} \\
\mathrm{~nm}\end{array}$ & $G_{f}$ & $\begin{array}{l}\rho_{R H} \\
\mathrm{~g} / \mathrm{cm}^{3}\end{array}$ & $w t$ & $\begin{array}{l}{\left[\mathrm{SO}_{4}^{2-}\right]} \\
\times 10^{-21} \mathrm{~mol} \\
\end{array}$ & $\begin{array}{l}\rho_{\text {eff }} \\
\mathrm{g} / \mathrm{cm}^{3}\end{array}$ \\
\hline \multirow{13}{*}{ PSL-SA } & \multirow{4}{*}{$5 \%$} & 40 & 1.16 & 1.60 & 0.69 & 200 & \\
\hline & & 100 & 1.06 & 1.60 & 0.69 & 1209 & \\
\hline & & 150 & 1.01 & 1.60 & 0.69 & 606 & \\
\hline & & 40 & 1.18 & 1.43 & 0.53 & 173 & \\
\hline & \multirow[t]{2}{*}{$30 \%$} & 100 & 1.07 & 1.42 & 0.53 & 888 & \\
\hline & & 150 & 1.04 & 1.42 & 0.53 & 1637 & \\
\hline & \multirow{4}{*}{$70 \%$} & 40 & 1.28 & 1.25 & 0.34 & 164 & \\
\hline & & 100 & 1.10 & 1.24 & 0.34 & 769 & \\
\hline & & 150 & 1.07 & 1.24 & 0.33 & 1616 & \\
\hline & & 40 & 1.42 & 1.17 & 0.25 & 186 & \\
\hline & \multirow[t]{3}{*}{$85 \%$} & 100 & 1.16 & 1.16 & 0.23 & 824 & \\
\hline & & 150 & 1.11 & 1.16 & 0.23 & 1807 & \\
\hline & & 40 & & & & $174 \pm 11$ & \\
\hline \multirow[t]{7}{*}{$\overline{\text { mole }_{S A}}$} & \multirow{3}{*}{$\begin{array}{l}30 \%- \\
85 \%\end{array}$} & 100 & & & & $827 \pm 60$ & \\
\hline & & 150 & & & & $1687 \pm 104$ & \\
\hline & & 40 & 1.22 & 1.77 & 1.00 & 359 & 0.86 \\
\hline & \multirow[t]{3}{*}{$5 \%$} & 100 & 1.08 & 1.77 & 1.00 & 1836 & 0.80 \\
\hline & & 150 & 1.05 & 1.77 & 1.00 & 3853 & 0.77 \\
\hline & & 40 & 1.19 & 1.77 & 1.00 & 302 & 1.02 \\
\hline & $30 \%$ & 100 & 1.07 & 1.77 & 1.00 & 1674 & 0.87 \\
\hline \multirow{7}{*}{$\begin{array}{l}\text { PSL-SA- } \\
\text { AM }\end{array}$} & & 150 & 1.05 & 1.77 & 1.00 & 3704 & 0.81 \\
\hline & & 40 & 1.22 & 1.77 & 1.00 & 363 & 0.85 \\
\hline & \multirow[t]{3}{*}{$70 \%$} & 100 & 1.08 & 1.77 & 1.00 & 1819 & 0.80 \\
\hline & & 150 & 1.05 & 1.77 & 1.00 & 3869 & 0.77 \\
\hline & & 40 & 1.40 & 1.21 & 0.37 & 195 & \\
\hline & \multirow[t]{2}{*}{$85 \%$} & 100 & 1.13 & 1.21 & 0.37 & 790 & \\
\hline & & 150 & 1.09 & 1.21 & 0.37 & 1696 & \\
\hline
\end{tabular}


Supplementary Table S3b. Moles of $\mathrm{SO}_{4}^{2-}$ calculated for PSL-SA and PSL-SA-TEA.

\begin{tabular}{|c|c|c|c|c|c|c|c|}
\hline & RH & $\begin{array}{c}D_{0} \\
\mathrm{~nm}\end{array}$ & $G_{f}$ & $\begin{array}{l}\rho_{R H} \\
\mathrm{~g} / \mathrm{cm}\end{array}$ & $w t$ & $\begin{array}{l}{\left[\mathrm{SO}_{4}^{2-}\right]} \\
\times 10^{-21} \mathrm{~mol}\end{array}$ & $\begin{array}{l}\text { SA:TEA } \\
\text { assumed }\end{array}$ \\
\hline \multirow{18}{*}{$\begin{array}{l}\text { PSL-SA- } \\
\text { TEA }\end{array}$} & & 40 & 1.24 & 1.19 & 1.00 & 122 & \multirow{3}{*}{$1: 2$} \\
\hline & $5 \%$ & 100 & 1.10 & 1.19 & 1.00 & 668 & \\
\hline & & 150 & 1.06 & 1.19 & 1.00 & 1368 & \\
\hline & \multirow{3}{*}{$5 \%$} & 40 & 1.24 & 1.23 & 0.99 & 152 & \multirow{3}{*}{ 1:1.5 } \\
\hline & & 100 & 1.10 & 1.23 & 0.99 & 828 & \\
\hline & & 150 & 1.06 & 1.23 & 0.99 & 1697 & \\
\hline & \multirow{3}{*}{$30 \%$} & 40 & 1.20 & 1.18 & 0.92 & 90 & \multirow{3}{*}{$1: 2$} \\
\hline & & 100 & 1.11 & 1.18 & 0.92 & 733 & \\
\hline & & 150 & 1.08 & 1.18 & 0.92 & 1725 & \\
\hline & \multirow{3}{*}{$70 \%$} & 40 & 1.20 & 1.15 & 0.72 & 68 & \multirow{3}{*}{$1: 2$} \\
\hline & & 100 & 1.10 & 1.15 & 0.72 & 556 & \\
\hline & & 150 & 1.07 & 1.15 & 0.72 & 1308 & \\
\hline & \multirow{3}{*}{$85 \%$} & 40 & 1.49 & 1.12 & 0.57 & 167 & \multirow{3}{*}{$1: 2$} \\
\hline & & 100 & 1.19 & 1.12 & 0.57 & 774 & \\
\hline & & 150 & 1.13 & 1.12 & 0.57 & 1605 & \\
\hline & \multirow{3}{*}{$85 \%$} & 40 & 1.49 & 1.12 & 0.54 & 193 & \multirow{3}{*}{$1: 1.5$} \\
\hline & & 100 & 1.19 & 1.12 & 0.54 & 897 & \\
\hline & & 150 & 1.13 & 1.12 & 0.54 & 1861 & \\
\hline
\end{tabular}


Supplementary Figure S5. Moles of $\mathrm{SO}_{4}^{2-}$ calculated for PSL-SA, PSL-SA-AM, and PSL-SA-TEA, as listed in Supplementary Tables S3a and S3b. The black line represents mean values for moles of $\mathrm{SO}_{4}^{2-}$ derived from hygroscopic growth of PSL-SA between $30 \%-85 \% \mathrm{RH}$ with $\pm 1 \sigma$ (red line) and $\pm 2 \sigma$ (blue line) uncertainty. For PSL-SA and PSL-SA-AM particles, the $\left[\mathrm{SO}_{4}^{2-}\right]$ for SA (square) and AS (circle) coating, respectively, is plotted. For PSL-SA-TEA particles, the $\left[\mathrm{SO}_{4}^{2-}\right]$ with assumptions of various coating material, including TEAS (up triangle), TEABS (down triangle), and TEABS/TEAS (1:1, diamond), is plotted. It was indicated that TEA can only partially neutralize coated $\mathrm{H}_{2} \mathrm{SO}_{4}$, i.e., TEABS/TEAS coating at $5 \% \mathrm{RH}$ and TEAS solution at $85 \% \mathrm{RH}$.
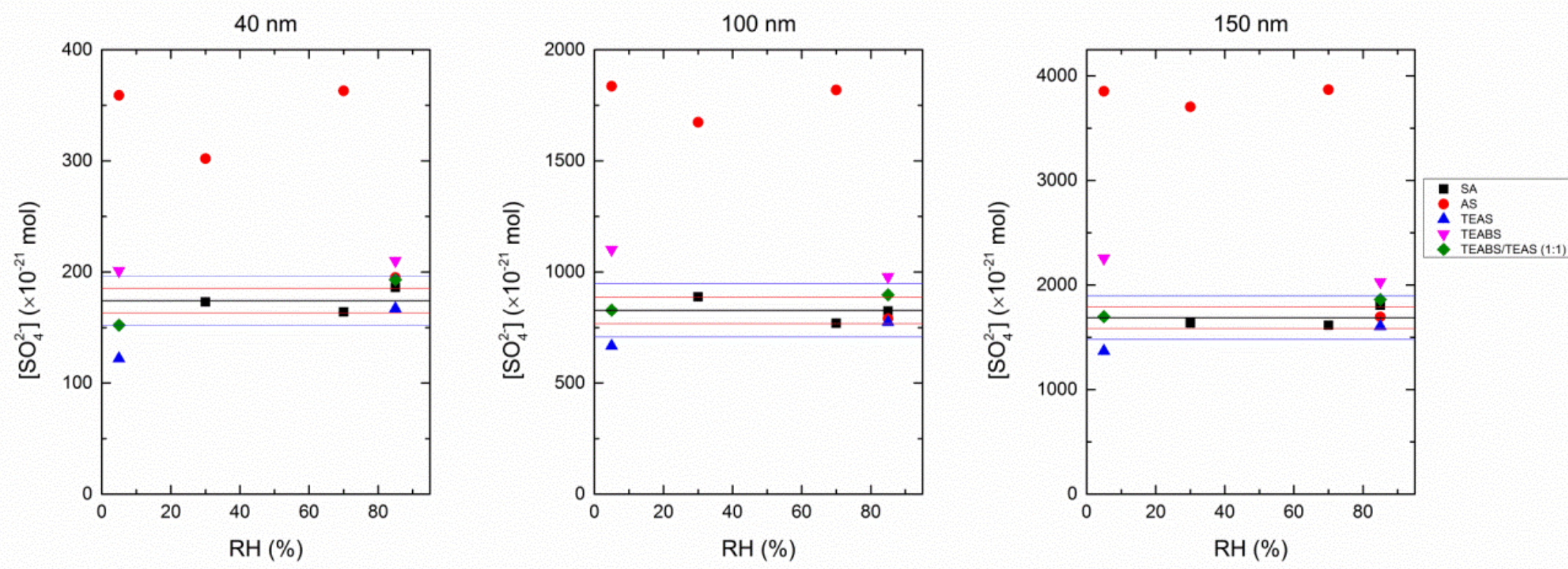


\section{Charring of OC in the TDMA-TD system}

There is a concern that heating of $\mathrm{BC}-\mathrm{BrC}$ can lead to charring of OC. BrC (mainly PAHs) can be the main OC for carbonaceous particles produced in fuel-rich (oxygen-deficient) flames (Slowik et al., 2004). Hence, charring would have occurred, if ever, during the particle generation where temperature was higher than $250{ }^{\circ} \mathrm{C}$, which is not evidenced in our morphology analysis.

Charring of OCs from particulate matters collected on the quartz filter has been well studied, and it mainly happens when the temperature is raised to $>250{ }^{\circ} \mathrm{C}$ (Chow et al., 2004). Kondo et al. (2011) reported that interferences in absorption measurements due to charring after heating particles to $300{ }^{\circ} \mathrm{C}$ or $400{ }^{\circ} \mathrm{C}$ were $1.7 \%$ and $4.6 \%$ in maximum and $0.4 \%$ and $1.8 \%$ on average, respectively. Also, constant relative intensities of $\mathrm{C}^{+}$to $\mathrm{C}^{+}$ions (which dominant the $\mathrm{BC}$ signal) were measured by AMS in CalNex and CARES studies using a thermal denuder at $245{ }^{\circ} \mathrm{C}$, indicating that charring did not occur (Cappa et al., 2012).

On the other hand, refractory sulfur-containing species was formed during the condensation of $\mathrm{H}_{2} \mathrm{SO}_{4}$ as evidenced in our EDX results. However, the amount of "refractory sulfur-containing species" was minor.

Hence, given the heating temperature of $250{ }^{\circ} \mathrm{C}$, we don't expect any significant charring of our $\mathrm{BC}-\mathrm{BrC}$ particles. 
9. Mie theory calculation with a core-shell configuration

The estimation of absorption and scattering cross section were performed by a MATLAB functions based on Mie theory (Mätzler, 2002).

The volume equivalent diameter was derived according to the equation:

$$
\frac{\pi}{6} d_{v e}^{3} \rho_{p}=\frac{\pi}{6} d_{m}^{3} \rho_{e f f}
$$

where $d_{v e}$ is the volume equivalent diameter, $d_{m}$ is the mobility diameter, $\rho_{p}$ is the particle density, and $\rho_{\text {eff }}$ is the effective particle density (DeCarlo et al., 2004). The particle density was derived from the mass fraction $(34 \%$ and $66 \%)$ and density $\left(1.3 \mathrm{~g} / \mathrm{cm}^{3}\right.$ and $\left.1.8 \mathrm{~g} / \mathrm{cm}^{3}\right)$ of OC and EC, respectively. The volume equivalent diameter was then determined to be $132.7 \mathrm{~nm}$ for $\mathrm{BC}-\mathrm{BrC}$ particles with a mobility diameter of $150 \mathrm{~nm}$. The shell thickness was defined as the difference between the volume equivalent diameters of fresh and processed $\mathrm{BC}-\mathrm{BrC}$ particles.

The complex refractive indices of fresh $\mathrm{BC}$-BrC particles were retrieved to be $2.00+0.20 \mathrm{i}$ from Mie "closure" calculations based on particle size, scattering, and absorption measurements. The shell refractive indices of pure sulfuric acid, ammonium sulfate and triethylaminium sulfate are 1.42, 1.50 and 1.42, respectively (Lavi et al., 2013). Under high humidity, the shell refractive indices of the corresponding solution are calculated according to the volume weighted mixing rule (Michel Flores et al., 2012). The water refractive index is 1.335, and the volume of solvent and water are derived using the E-AIM model. The absorption cross section under variable relative humidity conditions for different forms of coating was ready to be obtained using a coreshell configuration. Note that uniform coating of sulfate ammonium was assumed here, which would lead to overestimation of absorption below deliquescent relative humidity. $E_{a b s}$ was derived from the measured absorption cross section of fresh $\mathrm{BC}-\mathrm{BrC}$ and the calculated one of processed $\mathrm{BC}-\mathrm{BrC}$ according to:

$$
E_{a b s}=\frac{C_{a b s, \text { processed BC-BrC }}}{C_{a b s, \text { fresh BC-BrC }}}
$$

To investigate the effect of $R_{B C-B r C}$ over a large span, i.e. variable mass of coating, the model was performed in the range of $\left[\mathrm{SO}_{4}^{2-}\right] 10$-fold lower or higher than that in this study. 


\section{Reference}

Anderson, T.L., Ogren, J.A., 1998. Determining aerosol radiative properties using the TSI 3563 integrating nephelometer. Aerosol. Sci. Technol. 29, 57-69.

Biskos, G., Buseck, P.R., Martin, S.T., 2009. Hygroscopic growth of nucleation-mode acidic sulfate particles. J. Aerosol. Sci. 40, 338-347.

Bond, T.C., Bergstrom, R.W., 2006. Light absorption by carbonaceous particles: An investigative review. Aerosol. Sci. Technol. 40, 27-67.

Cappa, C.D., Onasch, T.B., Massoli, P., Worsnop, D.R., Bates, T.S., Cross, E.S., Davidovits, P., Hakala, J., Hayden, K.L., Jobson, B.T., Kolesar, K.R., Lack, D.A., Lerner, B.M., Li, S.M., Mellon, D., Nuaaman, I., Olfert, J.S., Petaja, T., Quinn, P.K., Song, C., Subramanian, R., Williams, E.J., Zaveri, R.A., 2012. Radiative absorption enhancements due to the mixing state of atmospheric black carbon. Science 337, 1078-1081.

Chow, J.C., Watson, J.G., Chen, L.W.A., Arnott, W.P., Moosmüller, H., Fung, K., 2004. Equivalence of Elemental Carbon by Thermal/Optical Reflectance and Transmittance with Different Temperature Protocols. Environmental Science \& Technology 38, 4414-4422.

Clegg, S.L., Qiu, C., Zhang, R., 2013. The deliquescence behaviour, solubilities, and densities of aqueous solutions of five methyl- and ethyl-aminium sulphate salts. Atmos. Environ. 73, 145-158.

DeCarlo, P.F., Slowik, J.G., Worsnop, D.R., Davidovits, P., Jimenez, J.L., 2004. Particle Morphology and Density Characterization by Combined Mobility and Aerodynamic Diameter Measurements. Part 1: Theory. Aerosol Sci. Technol. 38, 1185-1205.

Gibson, E.R., Gierlus, K.M., Hudson, P.K., Grassian, V.H., 2007. Generation of Internally Mixed Insoluble and Soluble Aerosol Particles to Investigate the Impact of Atmospheric Aging and Heterogeneous Processing on the CCN Activity of Mineral Dust Aerosol. Aerosol. Sci. Technol. 41, 914-924.

Kondo, Y., Sahu, L., Moteki, N., Khan, F., Takegawa, N., Liu, X., Koike, M., Miyakawa, T., 2011. Consistency and Traceability of Black Carbon Measurements Made by Laser-Induced Incandescence, Thermal-Optical Transmittance, and Filter-Based Photo-Absorption Techniques. Aerosol Sci. Technol. 45, 295-312.

Lavi, A., Bluvshtein, N., Segre, E., Segev, L., Flores, M., Rudich, Y., 2013. Thermochemical, Cloud Condensation Nucleation Ability, and Optical Properties of Alkyl Aminium Sulfate Aerosols. J. Phys. Chem. C 117, 22412-22421.

Li, L., Chen, J., Chen, H., Yang, X., Tang, Y., Zhang, R., 2011. Monitoring optical properties of aerosols with cavity ring-down spectroscopy. J. Aerosol Sci 42, 277-284. 
Linstrom, P.J., Mallard, W.G., 2014. NIST Chemistry WebBook, NIST Standard Reference Database Number 69. National Institute of Standards and Technology, Gaithersburg MD, 20899.

Mätzler, C., 2002. MATLAB Functions for Mie Scattering and Absorption Version 2, Research Report No. 2002-11. Institut für Angewandte Physik.

Michel Flores, J., Bar-Or, R.Z., Bluvshtein, N., Abo-Riziq, A., Kostinski, A., Borrmann, S., Koren, I., Koren, I., Rudich, Y., 2012. Absorbing aerosols at high relative humidity: linking hygroscopic growth to optical properties. Atmos. Chem. Phys. 12, 5511-5521.

Michela, A., Barbara, A., Antonio, T., Anna, C., 2008. Identification of large polycyclic aromatic hydrocarbons in carbon particulates formed in a fuel-rich premixed ethylene flame. Carbon 46, 2059-2066.

Slowik, J.G., Stainken, K., Davidovits, P., Williams, L.R., Jayne, J.T., Kolb, C.E., Worsnop, D.R., Rudich, Y., DeCarlo, P.F., Jimenez, J.L., 2004. Particle Morphology and Density Characterization by Combined Mobility and Aerodynamic Diameter Measurements. Part 2: Application to Combustion-Generated Soot Aerosols as a Function of Fuel Equivalence Ratio. Aerosol Sci. Technol. 38, 1206-1222.

Wexler, A.S., Clegg, S.L., 2002. Atmospheric aerosol models for systems including the ions H+, NH4+, Na+, SO42-, NO3-, Cl-, Br-, and H2O. J. Geophys. Res. D: Atmos. 107, ACH 14-11ACH 14-14.

Wiedensohler, A., 1988. An approximation of the bipolar charge distribution for particles in the submicron size range. J. Aerosol Sci 19, 387-389. 